\title{
Thermodynamic and Physical Property Estimation of Compounds Derived from the Fast Pyrolysis of Lignocellulosic Materials
}

\author{
Isabel Fonts, María Atienza-Martínez, Hans-Heinrich Carstensen, Mario Benés, \\ Anamaria Paiva Pinheiro Pires, Manuel Garcia-Perez, and Rafael Bilbao*
}

Cite This: Energy Fuels 2021, 35, 17114-17137

Read Online

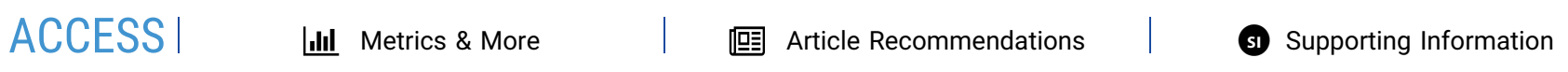

a
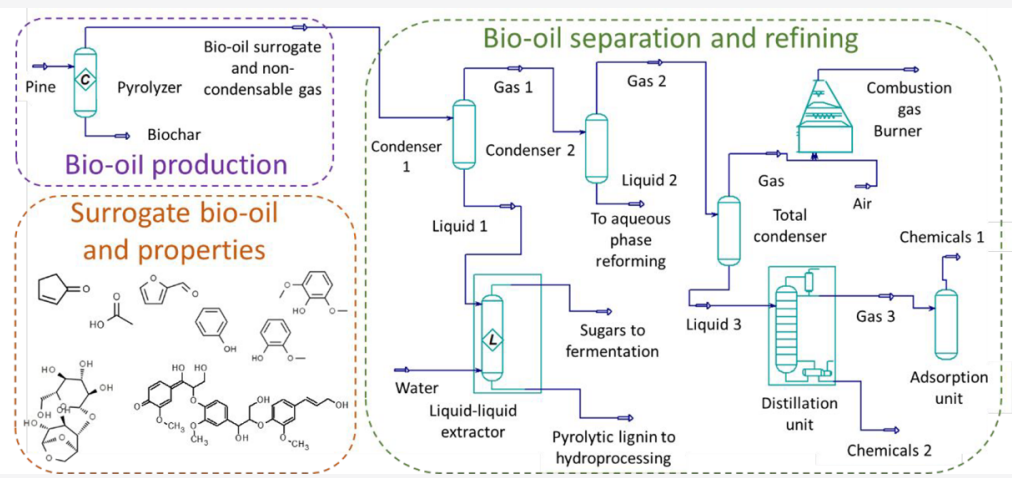

ABSTRACT: The development of biomass pyrolysis oil refineries is a very promising path for the production of biofuels and bioproducts from lignocellulosic materials. Given that bio-oil is a complex mixture of organic compounds, the production of valuable bioproducts may imply the use of different separation processes, such as distillation, selective condensation, crystallization based on melting points, liquid-liquid extraction or adsorption, and/or upgrading treatments, such as catalytic cracking or hydrodeoxygenation. In this context, the main objectives of this work are (1) to propose a simple but representative composition of the bio-oil, which can be used as a bio-oil surrogate, and (2) to determine selected thermodynamic, physical, and molecular properties of the organic compounds included in the bio-oil surrogate using different estimation methods and calculation procedures. These properties are critical temperature, critical pressure, critical volume, normal boiling point, enthalpy of vaporization, vapor pressure curves, normal melting point, enthalpy of fusion, heat capacities of gas, liquid, and solid, gas and liquid standard enthalpy of formation, gas standard Gibbs free energy of formation, Hansen solubility parameters, molecular volume, and molecular diameter. This group of properties has been selected for their possible application in the simulation or design of thermochemical, separation, and upgrading processes. Additionally, the suitability of the estimated thermodynamic properties and the proposed surrogate composition has been assessed by comparing experimental and literature data with the apparent enthalpy of formation of the bio-oil predicted from the weight-averaged contributions of the compounds as well as the heat required for the pyrolysis process at $500{ }^{\circ} \mathrm{C}$.

\section{INTRODUCTION}

One of the most promising platforms for the production of renewable fuels and chemicals is based on the production of bio-oil via fast pyrolysis of lignocellulosic biomass followed by its refining and/or upgrading. ${ }^{1}$ Pyrolysis bio-oil obtained from lignocellulosic biomass is a mixture of water (usually between 15 and $30 \mathrm{wt} \%$ ) and organic compounds produced through devolatilization, cracking, and thermal ejection of the main biomass components (cellulose, hemicellulose, lignin, and extractives) as well as secondary reactions of the primary pyrolysis products. ${ }^{2-4}$ The organic compounds present in biooil can be classified in the following chemical families: aldehydes, ketones, acids, furans, phenols, methoxyphenols, sugars, and oligomers. ${ }^{3,4}$ The molecular weights of the organic compounds in bio-oil range between those of light compounds
$\left(<\mathrm{C}_{4}\right)$ and those of three types of oligomers (pyrolytic lignin, humins, and hybrid oligomers). ${ }^{3-5}$ The myriad of chemical reactions and phenomena that take place during the pyrolysis process combined with the structural diversity of the biomass constituents cause pyrolysis bio-oil to be a very complex mixture. This complexity is caused by not only the presence of a large number of types of organic compounds but also the

Special Issue: 2021 Pioneers in Energy Research: Javier Bilbao

Received: May 31, 2021

Revised: July 23, 2021

Published: September 4, 2021

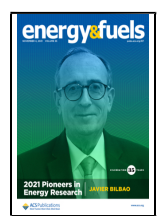


large range of molecular weights of these compounds and the combination of functionalities that are present in them. ${ }^{3-5}$

High-resolution mass spectrometry (HRMS) techniques used for petroleomic characterization enable the detection of compounds of very different molar masses from $50 \mathrm{~g} \mathrm{~mol}^{-1}$ to oligomeric fragments up to $100000 \mathrm{~g} \mathrm{~mol}^{-1}$ when electrospray ionization (ESI) is used. ${ }^{6}$ When this technique is applied to wood bio-oil, the presence of thousands of compounds, each of them with a single $\mathrm{C}_{c} \mathrm{H}_{h} \mathrm{~N}_{n} \mathrm{O}_{o} \mathrm{~S}_{s}$ molecular formula, is revealed. ${ }^{5,7}$ As a result of the numerous organic compounds found in bio-oil, only some of them, acetol, glycolaldehyde, acetic acid, levoglucosan, and cellobiosan, are usually detected in concentrations above $1 \%\left(1.0-13.7\right.$ wt \%). ${ }^{1,8}$ Acetol, glycolaldehyde, and acetic acid have already been isolated from pyrolysis liquids by means of various techniques, e.g., fractional condensation, aqueous phase distillation, precipitation with lime, or extraction with solvents, while levoglucosan has been separated together with other fermentable sugars to produce ethanol and lipids. ${ }^{1}$ The concentration of the other organic compounds in pyrolysis liquids is usually below $0.5 \mathrm{wt} \%$; therefore, it seems more interesting to attempt their commercialization as fractions (e.g., mono- and oligophenols, fermentable sugars, or anhydrosugars), because their separation as single compounds is technically challenging and costly and would only be commercially feasible for very high-value products. ${ }^{1}$ Pyrolytic lignin can be isolated as water insoluble and classified according to its molecular mass in lowmolecular-mass (LMM) lignin (molecular mass of $400 \mathrm{amu}$ and polydispersity of 1.7 ), which is $\mathrm{CH}_{2} \mathrm{Cl}_{2}$-soluble, and highmolecular-mass (HMM) lignin (molecular mass of $1050 \mathrm{amu}$ and polydispersity of 2.3 ), which is $\mathrm{CH}_{2} \mathrm{Cl}_{2}$-insoluble. Pyrolytic lignin is of interest because it is a promising starting material for the production of antioxidants, resins, adhesives, carbon fibers, or thermal-insulating materials, among others. ${ }^{1}$ Although there is evidence for the presence of other oligomers apart from pyrolytic lignin in bio-oil, such as humins and hybrid oligomers, they have not yet been isolated from the liquid matrix. ${ }^{5}$ On the other hand, all of these types of oligomers may participate in polymerization reactions during the hydrodeoxygenation of bio-oil. ${ }^{10}$

The different functional groups present in bio-oil provide, in principle, numerous possibilities for applications. At the same time, the presence of these functionalities also poses several difficulties because, for example, each different functional group might follow its own reactive behavior during the upgrading treatments. ${ }^{1,10}$

Bio-oil is an important biorefinery platform intermediate, because it can be used as biofuel and/or for the production of marketable bioproducts. The direct use of bio-oil as a fuel is challenging because of its relatively high oxygen content (greater than $40 \mathrm{wt} \%$ on a wet basis). To address this, alternative strategies have been proposed, including its upgrading during the pyrolysis reaction through catalytic cracking and in post-processing by hydrodeoxygenation or coprocessing with petroleum fractions. ${ }^{11}$ The production of valuable bioproducts implies the use of separation processes, such as distillation, selective condensation, crystallization based on melting points, liquid-liquid extraction, or selective adsorption. Bio-oil upgrading is a research area of high interest, $^{12,13}$ which includes the continuous search for improved separation processes. ${ }^{14}$ The complexity of these processes themselves and the multitude of parameters that may affect them make experimental investigations costly and tedious. Simulations of upgrading and separation processes of model bio-oils could allow for a priori assessments of the suitability of a selected method or the usefulness of performing parametric experimental studies. The availability of a simple but representative chemical composition of the pyrolysis biooil would help to accomplish such simulations and could also be useful for the design of the equipment involved in bio-oil processing. ${ }^{10}$ To successfully develop simulation models involving surrogate bio-oil compositions, knowledge of the physical and thermodynamic properties of all of the organic compounds considered as surrogates is required.

A search of the relevant literature yielded some studies, in which a surrogate composition for bio-oil or a fraction of biooil has been proposed. ${ }^{15-22}$ Ille et al. ${ }^{15}$ used experimental vapor liquid equilibrium data for the development of suitable surrogate mixtures by studying about 200 possibly suited components to represent the heavy fraction of the bio-oil, which typically condense at around $80-90{ }^{\circ} \mathrm{C}$. Dependent upon the choice of the surrogate mixture, their results differed more than $100 \%$, which demonstrates the importance of a carefully chosen surrogate. With regard to surrogate compositions representing the whole bio-oil, Westerhof et al. ${ }^{16}$ compared experimental results (water content of pyrolysis bio-oil and loss of organics from pyrolysis oil) to those obtained through an equilibrium flash condensation model, in which a surrogate composition of bio-oil was used to model the condenser as an equilibrium flash separator. This simple equilibrium stage condensation model (assuming that equilibrium is reached between the outgoing liquid and vapor streams with an ideal behavior of both gas and liquid phases) was applied to study the impact of the operating conditions on the condensation efficiency. The surrogate pyrolysis vapors proposed by Westerhof et al. ${ }^{17}$ consist of 12 discrete organic boiling point groups, $\mathrm{H}_{2} \mathrm{O}, \mathrm{N}_{2}$, and noncondensable pyrolysis gas. These authors choose one representative compound with well-known vapor pressures and Antoine constants for each boiling point group. However, despite the efforts of the authors to select model compounds for each boiling point group that are actually present in the bio-oil, two compounds not present in bio-oil, hydroquinone for the family of sugar molecules and $n$-butyric acid for those compounds with normal boiling points ranging between 427 and $450 \mathrm{~K}$, had to be included. According to these authors, this shortcoming was caused by difficulties finding Antoine constants for compounds of these two groups. ${ }^{17}$ Another weakness of this surrogate composition is that it is solely based on condensation properties of bio-oil. Hence, it considers only the boiling points for the selection of the surrogate composition of the bio-oil and ignores the distribution of chemical families and functional groups. The latter are relevant to simulate separation and upgrading processes. Surrogate mixtures of as much as five gas chromatography-mass spectrometry (GC-MS)-detectable compounds have been used to study the combustion characteristics of bio-oil, ${ }^{18-20}$ which seems insufficient taking into account the large number of bio-oil constituents. McVey et al. ${ }^{21}$ defined a surrogate for partially deoxygenated bio-oil, which was used to evaluate the continuous separation of benzene, toluene, and xylene by flash distillation. Krutof and Hawboldt ${ }^{22}$ used a bio-oil surrogate to model and predict the vapor-liquid equilibrium curves or vapor pressure curves. These authors proposed an interesting surrogate composition taking into account the presence of the typical bio-oil functional groups and a wide representation of 
Table 1. Organic Compounds Selected for the Surrogate Bio-oil

\begin{tabular}{|c|c|c|c|c|c|}
\hline family & compound & IUPAC name & CAS number & $\begin{array}{l}\text { molecular } \\
\text { formula }\end{array}$ & $\begin{array}{c}\text { molar mass } \\
\left(\mathrm{g} \mathrm{mol}^{-1}\right)\end{array}$ \\
\hline \multirow{4}{*}{$\begin{array}{l}\text { aldehydes and } \\
\text { ketones }\end{array}$} & glycolaldehyde & glycolaldehyde & $141-46-8$ & $\mathrm{C}_{2} \mathrm{H}_{4} \mathrm{O}_{2}$ & 60.1 \\
\hline & acetol & 1-hydroxyacetone & $116-09-6$ & $\mathrm{C}_{3} \mathrm{H}_{6} \mathrm{O}_{2}$ & 74.1 \\
\hline & 2-cyclopentenone & 2-cyclopenten-1-one & $930-30-3$ & $\mathrm{C}_{5} \mathrm{H}_{6} \mathrm{O}$ & 82.1 \\
\hline & 3-methyl-1,2-cyclopentanediene & 3-methyl-1,2-cyclopentanedione & $765-70-8$ & $\mathrm{C}_{6} \mathrm{H}_{8} \mathrm{O}_{2}$ & 112.1 \\
\hline \multirow[t]{3}{*}{ acids } & acetic acid & acetic acid & $64-19-7$ & $\mathrm{C}_{2} \mathrm{H}_{4} \mathrm{O}_{2}$ & 60.1 \\
\hline & propionic acid & propanoic acid & $79-09-4$ & $\mathrm{C}_{3} \mathrm{H}_{6} \mathrm{O}_{2}$ & 74.1 \\
\hline & formic acid & formic acid & $64-18-6$ & $\mathrm{CH}_{2} \mathrm{O}_{2}$ & 46.0 \\
\hline \multirow[t]{2}{*}{ furans } & furfural & furan-2-carbaldehyde & $98-01-1$ & $\mathrm{C}_{5} \mathrm{H}_{4} \mathrm{O}_{2}$ & 96.1 \\
\hline & $2(5 H)$-furanone & $2(5 H)$-furanone & $497-23-4$ & $\mathrm{C}_{4} \mathrm{H}_{4} \mathrm{O}_{2}$ & 84.1 \\
\hline \multirow{10}{*}{$\begin{array}{l}\text { phenols and } \\
\text { methoxyphenols }\end{array}$} & phenol & phenol & $108-95-2$ & $\mathrm{C}_{6} \mathrm{H}_{6} \mathrm{O}$ & 94.1 \\
\hline & guaiacol & 2-methoxyphenol & $90-05-1$ & $\mathrm{C}_{7} \mathrm{H}_{8} \mathrm{O}_{2}$ & 124.1 \\
\hline & creosol & 2-methoxy-4-methylphenol & $93-51-6$ & $\mathrm{C}_{8} \mathrm{H}_{10} \mathrm{O}_{2}$ & 138.2 \\
\hline & 4-ethylguaiacol & 4-ethyl-2-methoxyphenol & $2785-89-9$ & $\mathrm{C}_{9} \mathrm{H}_{12} \mathrm{O}_{2}$ & 152.2 \\
\hline & eugenol & 2-methoxy-4-prop-2-enylphenol & $97-53-0$ & $\mathrm{C}_{10} \mathrm{H}_{12} \mathrm{O}_{2}$ & 164.2 \\
\hline & catechol & benzene-1,2-diol & $120-80-9$ & $\mathrm{C}_{6} \mathrm{H}_{6} \mathrm{O}_{2}$ & 110.1 \\
\hline & syringol & 2,6-dimethoxyphenol & $91-10-1$ & $\mathrm{C}_{8} \mathrm{H}_{10} \mathrm{O}_{3}$ & 154.2 \\
\hline & 4-methylcatechol & 4-methylbenzene-1,2-diol & $452-86-8$ & $\mathrm{C}_{7} \mathrm{H}_{8} \mathrm{O}_{2}$ & 124.1 \\
\hline & vanillin & 4-hydroxy-3-methoxybenzaldehyde & $121-33-5$ & $\mathrm{C}_{8} \mathrm{H}_{8} \mathrm{O}_{3}$ & 152.1 \\
\hline & syringaldehyde & 4-hydroxy-3,5-dimethoxybenzaldehyde & $134-96-3$ & $\mathrm{C}_{9} \mathrm{H}_{10} \mathrm{O}_{4}$ & 182.2 \\
\hline \multirow[t]{2}{*}{ anhydrosugars } & levoglucosan & $(1 R, 2 S, 3 S, 4 R, 5 R)-6,8$-dioxabicyclo[3.2.1] octane-2,3,4-triol & 498-07-7 & $\mathrm{C}_{6} \mathrm{H}_{10} \mathrm{O}_{5}$ & 162.1 \\
\hline & cellobiosan & $\begin{array}{l}(2 S, 4 S, 5 S)-2 \text { - }[[(2 S, 3 R, 5 R)-3,4 \text {-dihydroxy-6,8- } \\
\text { dioxabicyclo[3.2.1] octan-2-yl] oxy]-6-(hydroxymethyl) } \\
\text { oxane-3,4,5-triol }\end{array}$ & $35405-71-1$ & $\mathrm{C}_{12} \mathrm{H}_{20} \mathrm{O}_{10}$ & 324.3 \\
\hline \multirow[t]{4}{*}{ oligomers } & HMM pyrolytic lignin & & & $\mathrm{C}_{81} \mathrm{H}_{78} \mathrm{O}_{25}$ & 1451.5 \\
\hline & LMM pyrolytic lignin & & & $\mathrm{C}_{30} \mathrm{H}_{34} \mathrm{O}_{11}$ & 570.6 \\
\hline & humin & & & $\mathrm{C}_{36} \mathrm{H}_{32} \mathrm{O}_{16}$ & 720.6 \\
\hline & hybrid oligomer & & & $\mathrm{C}_{70} \mathrm{H}_{82} \mathrm{O}_{34}$ & 1467.4 \\
\hline
\end{tabular}

boiling points, although there are other requirements, such as the concentration of families or elemental analysis of the biooil, that were not taken into account. This brief review demonstrates that the development of a representative composition for bio-oil is both needed and of interest.

Besides these surrogates for bio-oil, the research work developed by the group of Ranzi in the field of the detailed kinetic modeling of fast pyrolysis of biomass to produce bio-oil is worth mentioning. ${ }^{23-25}$ They describe raw biomass as a mixture of model components (cellulose, hemicellulose, three types of lignin, and two types of extractives) and assign temperature-dependent pyrolysis reactions to each component, which are assumed to react independently. On the basis of the elemental analysis and type of biomass, the biomass composition in terms of these hypothetical model components is estimated. Integration of the reactions of the surrogate composition for two different types of biomass (pine sawdust and grass) provides a detailed composition of pyrolysis products and char residue. ${ }^{24}$

Besides the establishment of the surrogates, the simulation of thermochemical, separation, and upgrading processes requires knowledge of the different thermodynamic and physical properties of the organic compounds of the bio-oil. As a result of the large number of compounds present in biooil, it is extremely difficult to provide experimental data for their different properties. Furthermore, bio-oil from lignocellulosic biomass contains compounds, such as oligomers, which are not well-characterized and for which thermodynamic and physical properties are unknown. As already mentioned, some of the oligomers present in the bio-oil have not yet been isolated, and therefore, their properties cannot be experimentally determined. For this reason, it is of considerable interest to apply and select non-experimental methods to estimate or calculate the values of these properties.

Non-experimental methods cover a wide spectrum of methods ranging from first-principle or $a b$ initio calculations to empirical correlations or estimations. It is worth remarking that, in this work, the term calculation will be used for $a b$ initio, because this methodology is based on fundamental physical laws, and the term estimate will be used for those methods, which use as input data parameters from the molecular structure (groups, atoms, etc.), other properties of the molecule, or both. The powerful quantum mechanical calculations are based on fundamental ( $a b$ initio) physical principles (solutions of the electronic Schrödinger equation ${ }^{26}$ ) and are, therefore, generally applicable without the need for experimental data, although, in practice, some empirical corrections are often applied to improve the results. The application range of such calculations is limited to simple systems: either gas-phase molecules or periodic condensed phases. Complex liquids, such as bio-oils, cannot yet be efficiently described quantum mechanically as a result of the large computational requirements. However, idealized Raman, infrared, ultraviolet (UV), or nuclear magnetic resonance (NMR) spectra of compounds can be predicted with acceptable accuracy, and these calculations allow adjustments for solvent effects. ${ }^{27}$ Furthermore, thermodynamic properties, such as enthalpies of formation, entropies, and heat capacities, can readily be determined for gas molecules by means of $a b$ initio calculations. The latter information can be used to calibrate estimation methods, such as group additivity concepts discussed later, or to define force constants for semi-empirical or molecular mechanic calculations. Routine and fast determinations of thermodynamic properties of complex 
Table 2. Concentration Proposed for Each Compound Included in the Surrogate Composition of Bio-oil and Intervals from the Literature for the Compounds and the Chemical Families

\begin{tabular}{|c|c|c|c|}
\hline family & compound & literature range $(\text { wt } \%)^{1,3,4,8,30-33}$ & proposed concentration (wt \%) \\
\hline \multirow[t]{4}{*}{ aldehydes and ketones } & glycolaldehyde & $1.0-13.7$ & 1.00 \\
\hline & acetol & $2.6-8.6$ & 6.72 \\
\hline & 2-cyclopentenone & $0.1-0.5$ & 0.50 \\
\hline & 3-methyl-1,2-cyclopentanediene & $0.3-0.5$ & 0.50 \\
\hline \multirow[t]{3}{*}{ acids } & acetic acid & $2.5-8.7$ & 8.70 \\
\hline & propionic acid & $0.2-2.8$ & 2.80 \\
\hline & formic acid & $0.5-1.0$ & 1.00 \\
\hline \multirow{3}{*}{$\begin{array}{l}\text { total aldehydes, ketones, and acids } \\
\text { furans }\end{array}$} & & $10.0-22.0$ & 21.22 \\
\hline & furfural & $0.1-0.6$ & 0.60 \\
\hline & $2(5 H)$-furanone & $0.1-0.8$ & 0.80 \\
\hline \multirow{11}{*}{$\begin{array}{l}\text { total furans } \\
\text { phenols and methoxyphenols }\end{array}$} & & $0.5-1.5$ & 1.40 \\
\hline & phenol & $0.1-0.9$ & 0.90 \\
\hline & guaiacol & $0.1-0.5$ & 0.22 \\
\hline & creosol & $0.1-0.5$ & 0.50 \\
\hline & 4-ethylguaiacol & $0.1-0.2$ & 0.20 \\
\hline & eugenol & $0.1-0.6$ & 0.60 \\
\hline & catechol & $0.2-0.9$ & 0.28 \\
\hline & syringol & $0.1-0.4$ & 0.10 \\
\hline & 4-methylcatechol & $0.1-0.5$ & 0.50 \\
\hline & vanillin & $0.1-1.5$ & 1.50 \\
\hline & syringaldehyde & $0.1-0.2$ & 0.20 \\
\hline \multirow{3}{*}{$\begin{array}{l}\text { total phenols and methoxyphenols } \\
\text { anhydrosugars }\end{array}$} & & $1.0-5.0$ & 5.00 \\
\hline & levoglucosan & $3.0-9.0$ & 6.50 \\
\hline & cellobiosan & $3.5-17$ & 3.50 \\
\hline \multirow{11}{*}{$\begin{array}{l}\text { total anhydrosugars } \\
\text { oligomers }\end{array}$} & & $10.0-20.0$ & 10.00 \\
\hline & HMM pyrolytic lignin & $5.0-11.0$ & 11.00 \\
\hline & LMM pyrolytic lignin & $5.0-18.0$ & 10.17 \\
\hline & pyrolytic lignin & $15.0-27.0$ & 21.17 \\
\hline & humin & $3.0-7.0$ & 7.00 \\
\hline & hybrid oligomer & $11.0-18.0$ & 11.00 \\
\hline & water & $19-30$ & 23.21 \\
\hline & & total & 100 \\
\hline & & average molar mass $\left(\mathrm{g} \mathrm{mol}^{-1}\right)$ & 478.0 \\
\hline & & average empirical formula & $\mathrm{C}_{1.12} \mathrm{H}_{2.30} \mathrm{O}$ \\
\hline & & average molecular formula & $\mathrm{C}_{16.9} \mathrm{H}_{34.5} \mathrm{O}_{15}$ \\
\hline
\end{tabular}

liquids are beyond the current state of the art, although codes for such molecular dynamic calculations exist. ${ }^{28}$ The advantage of estimation methods is that they allow for predictions of thermodynamic or physical properties with quite good accuracy by means of simple mathematical relationships between either some properties of the compound or between a computable structural descriptor of the compound and a property. $^{29}$

In this context, the main objectives of this work are (1) to propose a simple but representative chemical composition of pyrolysis bio-oil obtained from lignocellulosic biomass and (2) to determine selected thermodynamic, physical, and molecular properties of the organic compounds included in the proposed surrogate composition using $a b$ initio calculations and estimation methods. The properties to be determined have been selected in view of their possible use in the simulation or design of thermochemical, separation, and upgrading processes.

\section{COMPOSITION PROPOSED FOR SURROGATE BIO-OIL}

2.1. Methodology. A surrogate composition is proposed in this work for softwood bio-oil because it can be used (a) for
Table 3. Interval of Concentration for Each Functional Group from the Literature and Concentration Values Calculated from the Chemical Composition Proposed

\begin{tabular}{lcc}
$\begin{array}{c}\text { functional } \\
\text { group }\end{array}$ & $\begin{array}{c}\text { literature range } \\
\left(\mathrm{mmol} \mathrm{g}^{-1}\right)^{3,3}, 32\end{array}$ & $\begin{array}{c}\text { values in the surrogate bio-oil } \\
\left(\mathrm{mmol} \mathrm{g}^{-1}\right)\end{array}$ \\
\hline carbonyl & $2.8-5.3$ & 2.8 \\
carboxyl & $0.5-2.6$ & 2.2 \\
phenol OH & $0.9-3.9$ & 0.9 \\
aliphatic $\mathrm{OH}$ & $3.3-5.4$ & 5.5 \\
\hline
\end{tabular}

future simulations and (b) for use in this study to validate that our estimates of the properties of the surrogate compounds can be used to calculate the thermodynamic properties of the biooil.

The selection of the representative organic compounds for the surrogate bio-oil was based on results taken from the literature $\mathrm{r}^{1,3,4,8,30}$ taking into account: (1) the compounds with higher concentrations in softwood pyrolysis liquids, (2) the presence of compounds from the main chemical families (aldehydes, ketones, acids, furans, phenols, methoxyphenols, sugars, and oligomers) and containing the most representative functional groups quantified in softwood lignocellulosic pyrolysis liquids (carbonyl, carboxyl, phenol $\mathrm{OH}$, and aliphatic 
Table 4. Properties Reported, Methods Assessed for Their Estimation/Calculation, Type of Method, Input Data Required for Each Method, and Equation Number in Parentheses ${ }^{a}$

\begin{tabular}{|c|c|c|c|c|}
\hline property & symbol & type of method & input data (equation number) & reference \\
\hline \multicolumn{5}{|c|}{ Phase Change Properties } \\
\hline \multirow[t]{2}{*}{ critical temperature } & $T_{\mathrm{c}}$ & QSPR-QPPR & functional groups, $T_{\mathrm{b}}$ (eq $\mathrm{S} 1$ ) & Lydersen et al. ${ }^{45 b}$ \\
\hline & & QSPR-QPPR & functional groups, $T_{\mathrm{b}}$ (eq S2) & Joback $^{46 b}$ \\
\hline \multirow[t]{2}{*}{ critical pressure } & $P_{\mathrm{c}}$ & QSPR (GCM) & functional groups, $M$ (eq S3) & Lydersen et al. ${ }^{45}$ \\
\hline & & QSPR (GCM) & functional groups, $N$ (eq S4) & Joback $^{46}$ \\
\hline \multirow[t]{2}{*}{ critical volume } & $V_{\mathrm{c}}$ & QSPR (GCM) & functional groups (eq S5) & ${\text { Lydersen et } \mathrm{al}^{45}}^{45}$ \\
\hline & & QSPR (GCM) & functional groups (eq S6) & Joback $^{46}$ \\
\hline \multirow[t]{2}{*}{ normal boiling point ${ }^{c}$} & $T_{\mathrm{b}}$ & QSPR (GCM) & functional groups, $T_{\mathrm{b}}{ }^{d}$ (eqs $\mathrm{S} 7$ and $\mathrm{S} 8$ ) & Stein and Brown ${ }^{47}$ \\
\hline & & QSPR (GCM) & functional groups (eq S9) & Joback $^{46}$ \\
\hline \multirow{2}{*}{ enthalpy of vaporization $\left(T_{\mathrm{b}}\right)$} & $\Delta H_{\mathrm{vap}, T_{\mathrm{b}}}$ & QPPR & $T_{\mathcal{c}}, T_{\mathrm{b}}, P_{\mathrm{c}}($ eq $\mathrm{S} 10)$ & Riedel $^{48}$ \\
\hline & & QSPR (GCM) & functional groups (eq S11) & Joback $^{46}$ \\
\hline \multirow[t]{2}{*}{ enthalpy of vaporization (298.15 K) } & $\Delta H_{\text {vap }, 298 \mathrm{~K}}$ & QPPR & $\Delta H_{\mathrm{v}, T_{\mathrm{b}}}, T_{\mathrm{b}}, T_{\mathrm{c}}($ eq S12) & $\begin{array}{l}\text { Watson }{ }^{49} \text { modified by } \\
\text { Fishtine }^{50} \mathrm{Li} \text { et al. }\end{array}$ \\
\hline & & $\begin{array}{l}\text { thermodynamic equation } \\
\text { (TMD_VAP_ENTH) }\end{array}$ & $\Delta H_{\mathrm{v}, T_{\mathrm{b}}}, T_{\mathrm{b}}, C_{\mathrm{p}, \mathrm{liq}}, C_{\mathrm{p}, \mathrm{gas}}($ eq S13) & \\
\hline \multirow[t]{2}{*}{ normal melting point ${ }^{c}$} & $T_{\mathrm{m}}$ & QSPR (GCM) & functional groups (eq S14) & Pérez-Ponce et al. ${ }^{52}$ \\
\hline & & QSPR (GCM) & functional groups (eq S15) & Joback $^{46}$ \\
\hline \multirow{3}{*}{$\begin{array}{l}\text { enthalpy of fusion }\left(T_{\mathrm{m}}\right) \\
\text { vapor pressure curves }\end{array}$} & $\Delta H_{\text {fus }, T_{\mathrm{m}}}$ & QSPR (GCM) & functional groups (eq S16) & Joback $^{46}$ \\
\hline & $P_{\text {vap }}(T)$ & Clausius-Clapeyron & $\begin{array}{l}P_{\mathrm{vap} 1}, T_{\mathrm{b} 1}, \Delta H_{\mathrm{v}, T_{\mathrm{b} 1}}, T_{\mathrm{b} 2}(\text { eq } S 17) \text {, with } T_{\mathrm{b} 1} \\
\text { being the normal boiling point }\end{array}$ & \\
\hline & & QPPR & $T_{c}, P_{c}, T_{b}($ eqs $\mathrm{S} 18-\mathrm{S} 23)$ & Riedel $^{53}$ \\
\hline \multirow{4}{*}{ gas heat capacity at constant pressure } & & Ideal Gas Prop & ties & \\
\hline & $C_{\mathrm{p}, \mathrm{G}}$ and & QSPR (GCM) & $N_{i}(\text { eq S24) })^{e}$ & Harrison and Seaton ${ }^{54}$ \\
\hline & $C_{\mathrm{p}, \mathrm{G}}(T)$ & QSPR (GCM) & functional groups $\left(\right.$ eq S25) ${ }^{f}$ & Joback $^{46}$ \\
\hline & & $\begin{array}{l}\text { electronic structure } \\
\text { calculations, CBS-QB3 }\end{array}$ & molecular structure ${ }^{f}$ & \\
\hline \multirow[t]{2}{*}{ gas standard enthalpy of formation ${ }^{g}$} & $\Delta H_{\mathrm{f}, \mathrm{G}}^{\circ}$ & $\begin{array}{l}\text { electronic structure } \\
\text { calculations, CBS-QB3 }\end{array}$ & molecular structure & \\
\hline & & QSPR (GCM) & functional groups (eq S26) & Joback $^{46}$ \\
\hline \multirow[t]{2}{*}{$\begin{array}{l}\text { gas standard Gibbs free energy of } \\
\text { formation }^{g}\end{array}$} & $\Delta G_{\mathrm{f}, \mathrm{G}}^{\circ}$ & QSPR (GCM) & functional groups (eq S27) & Joback $^{46}$ \\
\hline & \multicolumn{4}{|c|}{ Condensed Phase Properties } \\
\hline $\begin{array}{l}\text { liquid heat capacity at constant } \\
\text { pressure }^{h}\end{array}$ & $C_{\mathrm{p}, \mathrm{L}}$ & QSPR (GCM) & functional groups (eq S28) & Chueh and Swanson ${ }^{55}$ \\
\hline solid heat capacity at constant pressure ${ }^{i}$ & $C_{\mathrm{p}, \mathrm{S}}$ & QSPR (GCM) & $N_{i}($ eq S29) & Hurst and Harrison ${ }^{56}$ \\
\hline \multirow[t]{2}{*}{$\begin{array}{l}\text { liquid standard enthalpy of formation } \\
\text { of individual compounds }{ }^{g}\end{array}$} & $\Delta H_{\mathrm{f}, \mathrm{L}}^{\circ}$ & $\begin{array}{l}\text { thermodynamic equation } \\
\text { (TMD_LIQ_ENTH) }\end{array}$ & $\Delta H_{\mathrm{f}, \mathrm{G}}^{\circ}, \Delta H_{\mathrm{vap}, 298 \mathrm{~K}}($ eq S30) & \\
\hline & & $\begin{array}{l}\text { enthalpy balance } \\
\left(\text { ENTH_BAL }^{j}\right)\end{array}$ & $\begin{array}{l}\text { elemental analysis, HHV (eqs S31 and S32 } \\
\text { for the HHV) }\end{array}$ & \\
\hline \multirow[t]{2}{*}{$\begin{array}{l}\text { liquid standard enthalpy of formation } \\
\text { of the whole bio-oil }\end{array}$} & $\Delta H_{\mathrm{f}, \mathrm{L} \text { bio-oil }}^{\circ}$ & $\begin{array}{l}\text { enthalpy balance } \\
\text { (ENTH_BAL) }\end{array}$ & $\begin{array}{l}\text { elemental analysis, HHV (eqs S31 and S32 } \\
\text { for the HHV) }\end{array}$ & \\
\hline & & weighted average (W_AVE) & $\begin{array}{l}\text { bio-oil surrogate composition, } \Delta H_{\mathrm{f}, \mathrm{L}}^{\circ} \text { (eq } \\
\text { S33) }\end{array}$ & \\
\hline \multirow[t]{2}{*}{ Hansen solubility parameters } & $\delta_{\mathrm{d}}, \delta_{\mathrm{p}}, \delta_{\mathrm{hb}}$ & QSPR (GCM) & functional groups (eqs S34-S36) & Stefanis and Panayiotou ${ }^{57}$ \\
\hline & & QSPR (GCM) & $\begin{array}{l}\text { functional groups (eqs } \mathrm{S} 37-\mathrm{S} 39 \text { and, for } \\
\Delta V \text {, eq } \mathrm{S} 40 \text { ) }\end{array}$ & Hansen $^{58}$ \\
\hline \multicolumn{5}{|c|}{ Molecular Properties } \\
\hline molecular volume & $\Delta V$ & $\begin{array}{l}\text { electronic structure } \\
\text { calculations, DFT }\end{array}$ & molecular structure & \\
\hline $\begin{array}{l}\text { recommended } a b \text { initio molecular } \\
\text { diameter }\end{array}$ & $D_{\text {mol }}$ & $\begin{array}{l}\text { electronic structure } \\
\text { calculations, DFT }\end{array}$ & molecular structure & \\
\hline
\end{tabular}

${ }^{a} N$, total number of atoms in the molecule; $N_{i}$, number of atoms of element $i$ in the molecule; TMD_VAP_ENTH, thermodynamic equation to determine the enthalpy of vaporization at $298.15 \mathrm{~K}$ (see eq S13 of the Supporting Information); TMD_LIQ_ENTH, thermodynamic equation to determine the liquid enthalpy of formation (see eq S30 of the Supporting Information); ENTH BAL, enthalpy balance equation of the combustion reaction of compound $i$ (see eq S31 of the Supporting Information); ENTH_BAL, enthalpy balance equation of the combustion reaction of the bio-oil (see eq S31 of the Supporting Information); W_AVE, weighted average equation for the calculation of the bio-oil apparent enthalpy of formation (see eq S33 of the Supporting Information); CBS-QB3, an electronic structure calculation method designed to calculate accurate thermodynamic properties (enthalpy, entropy, and heat capacity) for gas phase molecules; and DFT, density functional theory, electronic structure calculation method especially suitable for geometry calculations and derived properties, here, the molecular volume and diameter [specifically, the level B3LYP/6-311G(2d,d,p) was used]. ${ }^{b}$ Not used for HMM pyrolytic lignin and hybrid oligomer. ${ }^{c}$ At $101.3 \mathrm{kPa} .{ }^{d}$ According to Stein and Brown, $T_{\mathrm{b}}{ }^{*}$ is first calculated as a function of the molecule functional groups (eq S7 of the Supporting Information) and then $T_{\mathrm{b}}$ is calculated correcting $T_{\mathrm{b}}{ }^{*}$ according to eq $S 8$ of the Supporting Information. ${ }^{e} C_{\mathrm{p}, \mathrm{G}}$ value for $T$ between 300 and $1500 \mathrm{~K}$, as a unique value for all of the temperature interval. ${ }^{f_{\mathrm{p}, \mathrm{G}}}$ values as a function of the temperature; Joback for $T$ between 298 and $1000 \mathrm{~K}$ and CBS-QB3 for $T$ between 250 and $1500 \mathrm{~K}$ for HMM pyrolytic lignin, humin, and hybrid oligomer and between 298 and $2500 \mathrm{~K}$ for the rest of the molecules. ${ }^{g} \mathrm{At} 298.15 \mathrm{~K}$ and $101.3 \mathrm{kPa} .{ }^{h} \mathrm{C}_{\mathrm{p}, \mathrm{L}}$ 


\section{Table 4. continued}

value for $293.15 \mathrm{~K} .{ }^{i} C_{\mathrm{p}, \mathrm{S}}$ value for $298.15 \mathrm{~K} .{ }^{j}$ Method used to estimate the standard enthalpy of formation of the four oligomer molecules and the whole bio-oil. HHV of the four oligomer molecules was estimated according to Channiwala and Parikh ${ }^{59}$ and was determined experimentally for the whole bio-oil (eq S32 of the Supporting Information).

$\mathrm{OH})$, (3) the existence of compounds typically separated as water soluble and also water insoluble, and (4) the coverage of the whole range of molecular weights of the compounds present in pyrolysis liquids.

The concentration of each compound of the surrogate was determined using a generalized reduced gradient (GRG) nonlinear optimization method. They were constrained to fulfill the mass percentage intervals collected from the literature for each compound ${ }^{1,3,4,8,30-32}$ and chemical family ${ }^{33}$ (both shown in Table 2), the molar concentration ranges of carbonyls, carboxyls, phenolic $\mathrm{OH}$, and aliphatic $\mathrm{OH}^{3,31,32}$ shown in Table 3, and the elemental composition of a commercial softwood bio-oil supplied by BTG-BTL. The four functional groups were selected because they are crucial for understanding the changes occurring during the production and upgrading of bio-oil. The elemental analysis of the bio-oil was experimentally determined in a Leco CHN 268 series elemental analyzer, and the results are 43.39 wt \% C, 7.37 wt \% $\mathrm{H}, 0.14$ wt $\% \mathrm{~N}$, and, calculated by difference, 49.10 wt \% O (wet basis). Because none of the organic compounds selected for the surrogate composition contains nitrogen, the elemental analysis values were normalized to exclude the exiguous mass percentage of nitrogen, giving 43.45 wt $\% \mathrm{C}, 7.38 \mathrm{wt} \% \mathrm{H}$, and 49.17 wt \% O. In addition, the higher heating value (HHV) of the bio-oil was measured with a C2000 Ika calorimetric pump being $17.50 \mathrm{MJ} \mathrm{kg}^{-1}$ (wet basis). The elemental analysis and experimentally determined HHV were used to assess the validity of the surrogate composition and the estimated thermodynamic properties required in the calculation of the liquid standard enthalpy of formation of the bio-oil. Further information about BTG-BTL bio-oil characterization can be found elsewhere. ${ }^{34}$

2.2. Results. Table 1 lists the organic compounds selected for the softwood bio-oil surrogate as well as their International Union of Pure and Applied Chemistry (IUPAC) name, Chemical Abstract Service (CAS) number, molecular formula, and molar mass. This selection was performed taking into account the inclusion of compounds from all chemical families (aldehydes, ketones, acids, furans, phenols, methoxyphenols, and anhydrosugars), from all fractions obtained by a solvent fractionation scheme, ${ }^{9}$ and also compounds of high molar mass, namely, oligomers. Most of the compounds in the surrogate are those determined in higher concentrations by GC-MS. Apart from these, cellobiosan, which is detected by high-performance liquid chromatography (HPLC), was also incorporated as a result of its significant concentration in biooil. ${ }^{8}$ Lastly, four oligomeric molecules were chosen to be part of the surrogate: HMM pyrolytic lignin, LMM pyrolytic lignin, humin, and hybrid oligomer. The definition and structural formulas of HMM pyrolytic lignin, humin, and hybrid oligomer were taken from the literature and are presented in section S.1 of the Supporting Information. The structural formula of the LMM pyrolytic lignin molecule has been proposed in this work and is also shown in section S.1 of the Supporting Information. The molecular representation proposed by Terrell and Garcia-Perez ${ }^{35}\left[\mathrm{G}(\beta \mathrm{O} 4) \mathrm{G}(\beta \mathrm{O} 4) \mathrm{G}-\mathrm{H}_{2}\right]$ and the possible appearance of quinone groups during pyrolysis $^{36}$ were taken into account to define a plausible
LMM pyrolytic lignin structural formula. This molecular representation $\left[\mathrm{G}(\beta \mathrm{O} 4) \mathrm{G}(\beta \mathrm{O} 4) \mathrm{G}-\mathrm{H}_{2}\right]$ is based on three guaiacol monomer units (typical in softwood lignin) connected with $\beta-\mathrm{O}-4$ bonds, which are the most abundant bonds in lignin. The structural formula proposed can be seen in Figure S1 of the Supporting Information.

If needed, the selection of the surrogate compounds could be modified depending upon the type of biomass pyrolyzed, the pyrolysis and bio-oil recovery system operating conditions, or even the application of the surrogate. With regard to the type of biomass, lignin in hardwood is mostly formed by units of guaiacyl and syringyl, with a different proportion depending upon the species, while softwood lignin contains mainly guaiacyl units and a small portion of $p$-hydroxyphenyl units. Therefore, softwood-derived bio-oils have a higher content of guaiacols, while hardwood-derived bio-oils contain higher quantities of syringols and methanol. To define a surrogate for hardwood-derived bio-oils, it is crucial to include methanol, to augment the concentration of syringols and to select pyrolytic lignin structures mainly based on syringyl and guaiacyl units. If this surrogate is desired to study the modeling of fuel $\mathrm{NO}_{x}$ formation during bio-oil combustion, it would be of interest to include pyrrole in the surrogate. ${ }^{19}$

Table 2 shows the calculated concentrations for the compounds of the surrogate. It can be observed that the concentrations of each compound are within the intervals found in the literature. The same applies to the concentration ranges of the chemical families (see Table 2) and the functional groups (see Table 3), except for aliphatic $\mathrm{OH}$, which is slightly higher. The elemental analysis (wet basis) of the surrogate bio-oil calculated from the molecular formulas of each compound and their proposed concentrations is $42.45 \mathrm{wt}$ $\% \mathrm{C}, 7.28$ wt $\% \mathrm{H}$, and 50.27 wt \% O. The compositions of the real and suggested bio-oil agree within 1.1 wt \% for $\mathrm{C}$ and $\mathrm{O}$ and within 0.1 wt $\%$ for $\mathrm{H}$, which are within the experimental error of the elemental analysis.

On the basis of the mass percentages proposed, the average molar mass, the average empirical formula, and the average molecular formula of the surrogate have been determined (see Table 2). The average molar mass of the surrogate (478 g $\left.\mathrm{mol}^{-1}\right)$ is within the range given in the literature for wood biooil (400-500 $\left.\mathrm{g} \mathrm{mol}^{-1}\right) .^{30,37,38}$

\section{ESTIMATION OF THE PROPERTIES OF THE ORGANIC COMPOUNDS}

The thermodynamic, physical, and molecular properties to be determined in this work have been selected in view of possible needs in the simulation or design of thermochemical, separation, and upgrading processes involving bio-oil. The properties chosen to be estimated or calculated in this work are critical temperature, critical pressure, critical volume, normal boiling point, enthalpy of vaporization, vapor pressure curves, normal melting point, enthalpy of fusion, heat capacities of gas, liquid, and solid, gas and liquid standard enthalpy of formation, gas standard Gibbs free energy of formation, Hansen solubility parameters, molecular volume, and molecular diameter. 


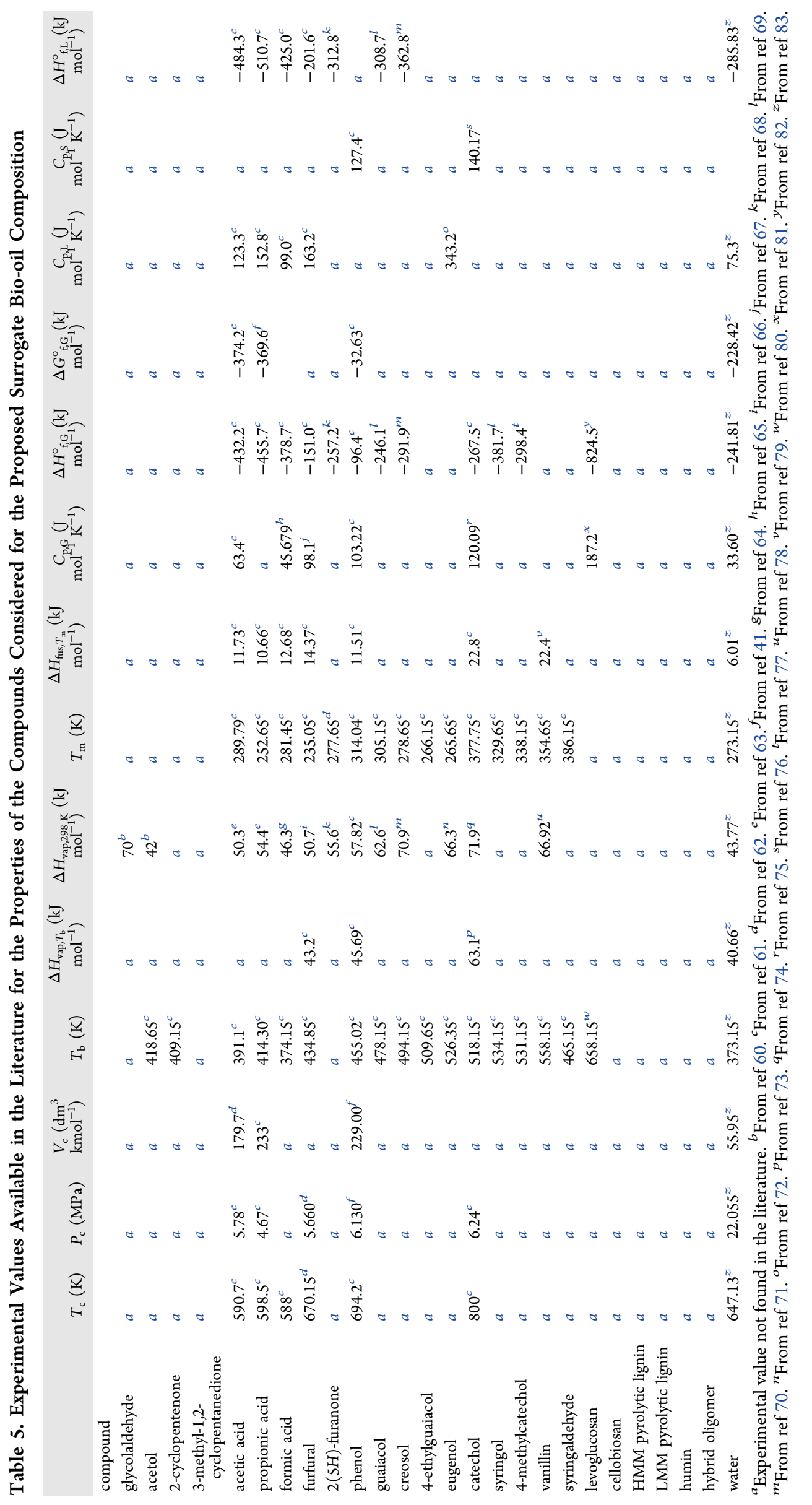


Table 6. Estimated Values of Critical Properties of the Compounds Included in the Surrogate Bio-oil and Differences with Experimental Values

\begin{tabular}{|c|c|c|c|c|c|c|}
\hline compound & $\begin{array}{l}T_{\mathrm{c}}(\mathrm{K}), \text { from } \\
\text { Joback }\end{array}$ & $\begin{array}{l}T_{c}(\mathrm{~K}), \text { from } \\
\text { Lydersen et al. }\end{array}$ & $\begin{array}{l}P_{\mathrm{c}}(\mathrm{MPa}) \\
\text { from Joback }\end{array}$ & $\begin{array}{l}P_{\mathrm{c}}(\mathrm{MPa}) \text {, from } \\
\text { Lydersen et al. }\end{array}$ & $\begin{array}{l}V_{\mathrm{c}}\left(\mathrm{dm}^{3} \mathrm{kmol}^{-1}\right) \\
\text { from Joback }\end{array}$ & $\begin{array}{l}V_{\mathrm{c}}\left(\mathrm{dm}^{3} \mathrm{kmol}^{-1}\right), \text { from } \\
\text { Lydersen et al. }\end{array}$ \\
\hline glycolaldehyde & 576.4 & 575.3 & 6.46 & 6.64 & 183.5 & 186.0 \\
\hline acetol & 595.5 & 595.7 & 5.48 & 5.74 & 228.5 & 228.0 \\
\hline 2-cyclopentenone & 637.0 & 637.9 & 5.00 & 5.63 & 250.5 & 253.0 \\
\hline 3-methyl-1.2-cyclopentanedione & 711.6 & 708.7 & 4.19 & 4.87 & 326.5 & 330.0 \\
\hline $\begin{array}{l}\text { aldehydes and ketones (family average } \\
\text { absolute difference) }\end{array}$ & $a$ & $a$ & $a$ & $a$ & $a$ & $a$ \\
\hline acetic acid & 587.8 & 591.6 & 5.73 & 6.51 & 171.5 & 175.0 \\
\hline propionic acid & 609.6 & 612.5 & 4.98 & 5.27 & 227.5 & 230.0 \\
\hline formic acid & 572.0 & 580.3 & 6.80 & 8.52 & 106.5 & 120.0 \\
\hline acids (family average absolute difference) & 10.0 & 7.6 & 0.18 & 0.66 & 6.8 & 3.9 \\
\hline furfural & 658.8 & 657.1 & 5.38 & 4.92 & 267.5 & 268.0 \\
\hline $2(5 H)$-furanone & 642.9 & 642.8 & 5.68 & 6.42 & 215.5 & 216.5 \\
\hline $\begin{array}{l}\text { furans (family average absolute } \\
\text { difference) }\end{array}$ & 11.4 & 13.0 & 0.28 & 0.74 & $a$ & $a$ \\
\hline phenol & 695.5 & 695.1 & 5.93 & 6.16 & 229.5 & 264.0 \\
\hline guaiacol & 700.4 & 697.1 & 4.91 & 4.73 & 303.5 & 338.0 \\
\hline creosol & 708.9 & 705.9 & 4.23 & 4.06 & 359.5 & 392.0 \\
\hline 4-ethylguaiacol & 718.0 & 714.5 & 3.75 & 3.55 & 415.5 & 447.0 \\
\hline eugenol & 734.8 & 727.6 & 3.51 & 3.27 & 452.5 & 482.0 \\
\hline catechol & 764.7 & 763.5 & 7.56 & 7.45 & 195.5 & 266.0 \\
\hline syringol & 754.0 & 748.2 & 4.14 & 3.84 & 377.5 & 412.0 \\
\hline 4-methylcatechol & 767.3 & 766.3 & 6.29 & 5.97 & 251.5 & 320.0 \\
\hline vanillin & 782.8 & 776.9 & 4.67 & 4.01 & 376.5 & 410.0 \\
\hline syringaldehyde & 632.5 & 626.5 & 3.95 & 3.35 & 450.5 & 484.0 \\
\hline $\begin{array}{l}\text { phenols and methoxyphenols (family } \\
\text { average absolute difference) }\end{array}$ & 18.3 & 18.7 & 0.76 & 0.62 & 0.5 & 35.0 \\
\hline levoglucosan & 835.2 & 829.3 & 5.70 & 4.53 & 365.5 & 384.5 \\
\hline cellobiosan & 1439.6 & 1472.6 & 4.02 & 2.61 & 726.5 & 751.5 \\
\hline $\begin{array}{l}\text { anhydrosugars (family average absolute } \\
\text { difference) }\end{array}$ & $a$ & $a$ & $a$ & $a$ & $a$ & $a$ \\
\hline HMM pyrolytic lignin & $-5847.7^{b}$ & $-3207.6^{b}$ & 0.38 & 0.51 & 3589.5 & 3717.0 \\
\hline LMM pyrolytic lignin & 1547.2 & 1649.7 & 1.39 & 1.23 & 1543.5 & 1510.0 \\
\hline humin & 3202.7 & 3644.3 & 1.43 & 1.00 & 1928.5 & 1833.0 \\
\hline hybrid oligomer & $-766.7^{b}$ & $-632.6^{b}$ & 0.54 & 0.53 & 3689.5 & 3703.0 \\
\hline global average absolute difference & 13.0 & 12.2 & 0.43 & 0.66 & 4.7 & 14.2 \\
\hline
\end{tabular}

${ }^{a}$ Differences were not calculated because no experimental values for any of the compounds of this family are available. ${ }^{b}$ Negative values are unreasonable.

Estimation methods can, among other criteria, be classified according to the type of required input data. ${ }^{39}$ Quantitative property-property relationships (QPPRs) use mathematical models that relate a certain property to other already available properties, while quantitative structure-property relationships (QSPRs) primarily base their estimations on the structure of the compounds by applying mathematical models that use fragment contributions and structural descriptors. ${ }^{39,40}$ QPPRs can arise from fundamental thermodynamic relationships, such as the Clausius-Clapeyron equation, or from fundamental relationships modified by empirical parameters and from correlations between properties described by regression models. QSPRs need only knowledge of the chemical structure of a compound, such as the number of fragments (atoms, bonds, or groups of atoms in a molecule) or other structural information to estimate the properties. ${ }^{39,41}$ Among the most commonly applied QSPR approaches for the estimation of thermodynamic properties are group contribution methods (GCMs). GCMs assume that a property in question for a compound depends upon additive contributions from each fragment (bonds, functional groups, etc.) of which the compound is composed. Such fragmental contributions 
Table 7. Estimated Values of $T_{\mathrm{b}}, \Delta H_{\mathrm{vap}, T_{\mathrm{b}}}$, and $\Delta H_{\mathrm{vap}, 298 \mathrm{~K}}$ of the Organic Compounds Included in the Surrogate Bio-oil and Differences with Experimental Values

\begin{tabular}{|c|c|c|c|c|c|c|}
\hline compound & $\begin{array}{c}T_{\mathrm{b}}(\mathrm{K}) \\
\text { from } \\
\text { Joback }\end{array}$ & $\begin{array}{l}T_{\mathrm{b}}(\mathrm{K}) \text {, from } \\
\text { Stein and Brown }\end{array}$ & 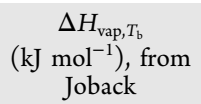 & $\begin{array}{c}\Delta H_{\text {vap }, T_{\mathrm{b}}} \\
\left(\mathrm{kJ} \mathrm{mol}^{-1}\right) \text {, from } \\
\text { Riedel }^{\text {Ried }}\end{array}$ & $\begin{array}{c}\Delta H_{\text {vap }} 298 \mathrm{~K} \\
\left(\mathrm{kJJ}^{-1} \mathrm{~mol}^{-}\right) \text {, from } \\
\text { Watson }\end{array}$ & $\begin{array}{l}\Delta H_{\text {vap.298 K }}\left(\mathrm{kJ} \mathrm{mol}^{-1}\right), \\
\text { from TMD_VAP_ENTH }\end{array}$ \\
\hline glycolaldehyde & 386.2 & 399.5 & 43.4 & 48.6 & 52.1 & 49.1 \\
\hline acetol & 414.2 & 409.1 & 45.7 & 50.1 & 56.4 & 54.5 \\
\hline 2-cyclopentenone & 400.9 & 406.8 & 31.8 & 37.4 & 36.7 & 38.6 \\
\hline 3-methyl-1.2-cyclopentanedione & 487.8 & 478.8 & 37.7 & 46.6 & 47.1 & 53.0 \\
\hline $\begin{array}{l}\text { aldehydes and ketones (family } \\
\text { average absolute difference) }\end{array}$ & 6.3 & 6.0 & $a$ & $a$ & 16.1 & 16.7 \\
\hline acetic acid & 390.8 & 395.5 & 37.2 & 40.4 & 42.9 & 42.8 \\
\hline propionic acid & 413.7 & 418.2 & 39.4 & 44.8 & 47.9 & 46.6 \\
\hline formic acid & 367.3 & 374.1 & 34.8 & 37.1 & 38.8 & 38.9 \\
\hline $\begin{array}{l}\text { acids (family average absolute } \\
\text { difference) }\end{array}$ & 2.5 & 2.8 & $a$ & $a$ & 7.1 & 7.6 \\
\hline furfural & 412.8 & 429.7 & 39.8 & 42.5 & 51.0 & 52.1 \\
\hline $2(5 H)$-furanone & 405.0 & 412.8 & 34.1 & 39.4 & 45.6 & 48.5 \\
\hline $\begin{array}{l}\text { furans (family average absolute } \\
\text { difference) }\end{array}$ & 22.0 & 5.2 & 3.4 & 0.7 & 5.2 & 4.3 \\
\hline phenol & 439.2 & 443.2 & 43.6 & 46.7 & 55.0 & 55.8 \\
\hline guaiacol & 489.5 & 484.6 & 48.9 & 50.0 & 61.6 & 64.2 \\
\hline creosol & 517.3 & 503.5 & 51.8 & 51.9 & 67.1 & 69.5 \\
\hline 4-ethylguaiacol & 540.2 & 521.6 & 54.0 & 53.8 & 71.9 & 76.6 \\
\hline eugenol & 559.8 & 537.4 & 55.5 & 55.4 & 75.2 & 86.9 \\
\hline catechol & 519.8 & 502.9 & 56.6 & 52.0 & 77.8 & 81.2 \\
\hline syringol & 539.7 & 522.2 & 54.2 & 57.7 & 73.0 & 78.9 \\
\hline 4-methylcatechol & 547.7 & 520.9 & 59.5 & 62.5 & 78.1 & 79.3 \\
\hline vanillin & 566.0 & 547.5 & 58.5 & 62.6 & 80.1 & 90.0 \\
\hline syringaldehyde & 616.3 & 578.6 & 63.8 & 54.3 & 84.7 & 87.1 \\
\hline $\begin{array}{l}\text { phenols and methoxyphenols (family } \\
\text { average absolute difference) }\end{array}$ & 29.7 & 21.2 & 4.3 & 6.0 & 5.9 & 9.7 \\
\hline levoglucosan & 675.3 & 586.9 & 87.2 & 132.8 & 138.8 & 150.0 \\
\hline cellobiosan & 1139.4 & 800.7 & 156.7 & 177.6 & 262.7 & 438.9 \\
\hline $\begin{array}{l}\text { anhydrosugars (family average } \\
\text { absolute difference) }\end{array}$ & 17.2 & 71.2 & $a$ & $a$ & $a$ & $a$ \\
\hline HMM pyrolytic lignin & 3496.5 & 1959.9 & 381.1 & $b$ & $b$ & 1961.8 \\
\hline LMM pyrolytic lignin & 1637.0 & 1047.0 & 190.9 & 52.2 & 254.0 & 534.9 \\
\hline humin & 2134.0 & 1272.4 & 264.1 & 32.7 & 292.8 & 1010.2 \\
\hline hybrid oligomer & 4126.4 & 2157.4 & 530.5 & $b$ & $b$ & 2923.5 \\
\hline global average absolute difference & 21.0 & 18.2 & 4.0 & 4.3 & 7.7 & 9.4 \\
\hline
\end{tabular}

${ }^{a}$ Differences were not calculated because no experimental values for this family are available. ${ }^{b}$ These values were not estimated because this method requires $T_{\mathcal{c}}$, and the $T_{\mathrm{c}}$ values estimated for these molecules were negative (see Table 6).

(group contribution) have traditionally been derived from experimental values. ${ }^{39}$ Different GCMs have been developed for property estimations of pure components, e.g., boiling point, ideal gas thermal properties, enthalpies of vaporization and fusion, solid and liquid heat capacities, density, viscosity, liquid and thermal conductivity, and diffusivity. ${ }^{40,41}$ They can be applied to a wide range of classes of compounds. ${ }^{39}$

The physical and thermodynamic properties of the compounds estimated or calculated in this work are shown in Table 4, together with the method used and the input data required. While most of the methods listed in Table 4 are likely well-known, it has been considered interesting to describe more in depth the $a b$ initio or electronic structure calculations in section S.2 of the Supporting Information. ${ }^{42,43}$ The ab initio data calculated in this study are for individual molecules, meaning at perfect gas conditions, and were carried out with Gaussian 16, Revision B.01 software. ${ }^{44}$ The nomenclature, equations used (eqs $\mathrm{S} 1-\mathrm{S} 40$ of the Supporting Information), 


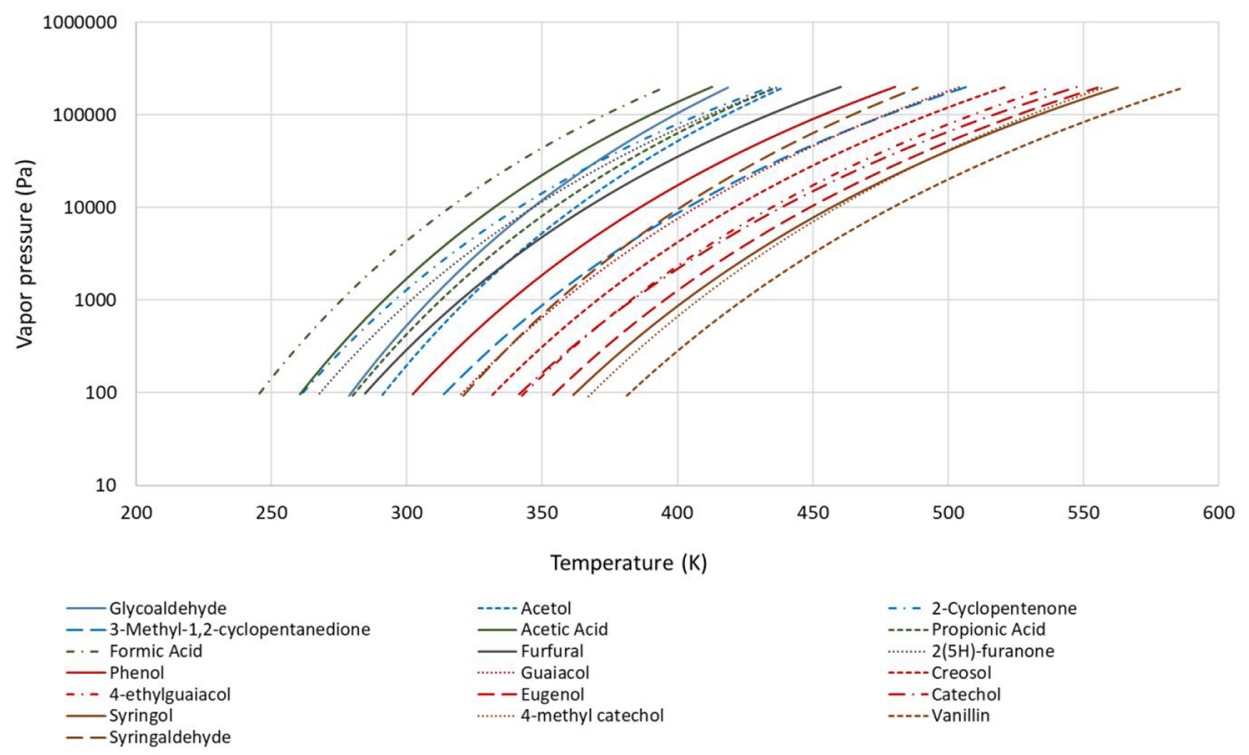

Figure 1. Vapor pressure curves of specific compounds of the bio-oil.

and functional groups considered are presented in section S.3 of the Supporting Information. The functional groups considered for the estimation of the properties with the different GCMs used are shown in Tables S1-S5 of the Supporting Information.

3.1. Methodology Used. The procedure used for the determination of the properties is summarized as follows: (1) A thorough literature search of the tabulated data was performed to compile as many values as possible. Only experimental values of the properties were considered and collected. When available, the reported experimental data were used, both to validate the estimates made in this work and as input data for the calculation of other properties. For example, the experimental boiling points $\left(T_{\mathrm{b}}\right)$ collected were used for the estimation of the critical temperature $\left(T_{\mathrm{c}}\right)$ following the Joback method (see input data in Table 4). The experimental values collected are presented in Table 5.(2) Thermodynamic and physical properties of all of the compounds used in the surrogate bio-oil were estimated/calculated using the methods shown in Table 4. As seen in Table 4, some of the properties were calculated according to thermodynamic (TMD) equations and enthalpy balances (ENTH_BAL). When the liquid enthalpy of formation of the oligomer compounds was calculated according to ENTH BAL (eq S31 of the Supporting Information), the elemental composition was taken from their molecular formula and the HHV following Channiwala and Parikh. ${ }^{59}$ Properties of the compounds were calculated/estimated assuming $100 \%$ purity. In general, the methods were used for the estimation of the corresponding property for all organic compounds of the surrogate bio-oil. Cases in which a method was only used for selected molecules are documented in Table 4, and the reason will be discussed in the Results. (3) When more than one method was used to determine a certain thermodynamic or physical property of a compound, the suitability of each method was assessed by comparison to the available experimental value (see Table 5). The most appropriate estimation method was chosen as the method that gave the lowest average absolute difference with respect to the available experimental values of the compounds of the same family. If no experimental values of a property were available for any of the compounds of a chemical family, the most appropriate estimation method was chosen as the method that gave the lowest average absolute difference with respect to the available experimental values of that property for all other families. (4) When a property was needed for the calculation/estimation of other properties (input data of Table 4), the experimental value was used if available. If not, the estimated value obtained by the most appropriate method was used. The use as input data of the available experimental values or values estimated with the most suitable method among those used may lead to differences in some estimated values if compared to databases using exclusively one method, such as Joback, for the estimation of these properties. (5) To assess both our estimates and the proposed surrogate composition, the apparent enthalpy of the bio-oil calculated as the weighted average of the enthalpies of formation of the surrogate compounds (eq S33 of the Supporting Information) was compared to that calculated from the enthalpy balance of the combustion reaction using the experimentally determined elemental analysis and the HHV of the BTG bio-oil. Lastly, the enthalpy balance of the fast pyrolysis of pine considering the reactants (pine) at $25{ }^{\circ} \mathrm{C}$ and the products (char, $\mathrm{CO}, \mathrm{CO}_{2}$, $\mathrm{CH}_{4}$, and surrogate bio-oil) at $500{ }^{\circ} \mathrm{C}$ was carried out using the proposed composition of the surrogate bio-oil and the thermodynamic properties determined in this work, with the aim of determining the heat for pyrolysis. The heat for pyrolysis usually refers to the energy that needs to be supplied (i.e., the total energy consumed during pyrolysis, including sensible enthalpy and enthalpy of reaction). In the enthalpy balance, it has been taken into account that, at $500{ }^{\circ} \mathrm{C}$, gas species, water, and most of the organic compounds are in the gas phase, because their boiling points are lower than the pyrolysis temperature $\left(500{ }^{\circ} \mathrm{C}\right)$, and that cellobiosan, HMM pyrolytic lignin, LMM pyrolytic lignin, humin, and hybrid oligomer would be in the liquid phase (probably as aerosols). The pine, gas, and char analysis and the product distribution have been taken from ref 84 , with the ratio between the quantity of carrier gas, $\mathrm{N}_{2}$, and the pyrolyzed pine taken from ref 85 and the specific heat capacity of char taken from ref 86 . 
Table 8. Estimated Values of $T_{\mathrm{m}}$ and $\Delta H_{\text {fus, } T_{\mathrm{m}}}$ of the Compounds Included in the Surrogate Bio-oil and Differences with Experimental Values

\begin{tabular}{|c|c|c|c|}
\hline compound & $\begin{array}{l}T_{\mathrm{m}}(\mathrm{K}), \\
\text { from } \\
\text { Joback }\end{array}$ & $\begin{array}{l}T_{\mathrm{m}}(\mathrm{K}) \\
\text { from Pérez- } \\
\text { Ponce }\end{array}$ & $\begin{array}{c}\Delta H_{\text {fus, } T_{\mathrm{m}}} \\
\left(\mathrm{kJ} \mathrm{mol} \mathrm{mol}^{-1}\right), \\
\text { from Joback }\end{array}$ \\
\hline glycolaldehyde & 215 & 244 & 7.3 \\
\hline acetol & 234 & 266 & 9.2 \\
\hline 2-cyclopentenone & 230 & 257 & 2.3 \\
\hline 3-methyl-1.2-cyclopentanedione & 305 & 315 & 4.2 \\
\hline $\begin{array}{l}\text { aldehydes and ketones (family } \\
\text { average absolute difference) }\end{array}$ & $a$ & $a$ & $a$ \\
\hline acetic acid & 273 & 259 & 11.1 \\
\hline propionic acid & 284 & 266 & 13.7 \\
\hline formic acid & 278 & 272 & 10.2 \\
\hline $\begin{array}{l}\text { acids (family average absolute } \\
\text { difference) }\end{array}$ & 17.3 & 18.1 & 2.1 \\
\hline furfural & 244 & 282 & 13.9 \\
\hline $2(5 H)$-furanone & 246 & 275 & 7.7 \\
\hline $\begin{array}{l}\text { furans (family average absolute } \\
\text { difference) }\end{array}$ & 8.8 & 46.7 & 0.5 \\
\hline phenol & 283 & 277 & 11.5 \\
\hline guaiacol & 329 & 308 & 14.9 \\
\hline creosol & 353 & 331 & 17.1 \\
\hline 4-ethylguaiacol & 364 & 338 & 19.7 \\
\hline eugenol & 374 & 342 & 21.0 \\
\hline catechol & 395 & 357 & 17.3 \\
\hline syringol & 375 & 338 & 18.3 \\
\hline 4-methylcatechol & 419 & 380 & 19.5 \\
\hline vanillin & 395 & 376 & 19.4 \\
\hline syringaldehyde & 441 & 407 & 22.8 \\
\hline $\begin{array}{l}\text { phenols and methoxyphenols } \\
\text { (family average absolute } \\
\text { difference) }\end{array}$ & 57.3 & 35.4 & 2.8 \\
\hline levoglucosan & 409 & 414 & 34.8 \\
\hline cellobiosan & 698 & 640 & 67.9 \\
\hline $\begin{array}{l}\text { anhydrosugars (family average } \\
\text { absolute difference) }\end{array}$ & $a$ & $a$ & $a$ \\
\hline HMM pyrolytic lignin & 2738 & 2334 & 216.6 \\
\hline LMM pyrolytic lignin & 986 & 936 & 67.3 \\
\hline humin & 1312 & 1552 & 127.4 \\
\hline hybrid oligomer & 2746 & 2466 & 251.3 \\
\hline global average absolute difference & 45.2 & 32.5 & 2.2 \\
\hline
\end{tabular}

3.2. Results. Table 5 shows the experimental values of the properties available in the literature. These experimental values will be used to assess the validity of our estimates and to choose the most appropriate estimation method among those used.

3.2.1. Phase Change Properties of Individual Compounds. 3.2.1.1. Critical Properties. As shown in Table 4, the estimation of these properties for the compounds considered for the proposed surrogate bio-oil composition has been carried out according to the QSPR-QPPR methods developed by Lydersen et al. ${ }^{45}$ and Joback. ${ }^{46}$ Table 6 shows the estimated values of the critical properties of the compounds included in the proposed surrogate for bio-oil. When experimental values are available, the average absolute difference between estimated and experimental data for each family is also shown and the differences for the methods providing the best estimation for a family or for the whole bio-oil compounds are marked in bold.

From the comparison of $T_{\mathrm{c}}$ values, it can be concluded that both estimation methods yield good estimates. The results from the Joback method are slightly better for furans (family average difference of $11.4 \mathrm{~K}$ ) and phenols and methoxyphenols (family average difference $18.3 \mathrm{~K}$ ), while the Lydersen et al. method yields better predictions for acids (family average difference of $7.6 \mathrm{~K}$ ) and the surrogate bio-oil compounds (global average absolute difference of $12.2 \mathrm{~K}$ ). The estimated $T_{\mathrm{c}}$ values for cellobiosan, LMM pyrolytic lignin, and humin are very high and should be treated with caution, because these molecules are bigger than those usually used in the development of GCMs. Both methods result in unreasonable values (negative) for HMM pyrolytic lignin and hybrid oligomer. Therefore, the estimations of both $\Delta H_{\mathrm{vap}, T_{\mathrm{b}}}$ according to Riedel (eq S10 of the Supporting Information) and $\Delta H_{\mathrm{vap}, 298 \mathrm{~K}}$ according to Watson (eq S12 of the Supporting Information) for these two molecules could not be carried out because $T_{c}$ is required as input data (see Table 4).

With regard to $P_{c}$, the differences between the estimated and experimental values are on average always less than $0.76 \mathrm{MPa}$ and quite similar for both methods (Joback and Lydersen et al.). The averaged overall absolute difference is smaller for the Joback method (0.43 $\mathrm{MPa})$.

$V_{\text {c }}$ values were also estimated by the Lydersen et al. and Joback methods. Experimental values are only available for a very small number of compounds used in the surrogate bio-oil (see Table 5). The $V_{c}$ values of acids are relatively wellestimated with both methods, while the Joback method estimates $V_{\mathrm{c}}$ of phenols and methoxyphenols more accurately than the Lydersen et al. method.

3.2.1.2. Normal Boiling Points, Enthalpy of Vaporization, and Vapor Pressure Curves. 3.2.1.2.1. Normal Boiling Points. Separation processes that could be included within a biorefinery scheme based on biomass fast pyrolysis are selective condensation (mainly at atmospheric pressure) and distillation. The selective condensation of the pyrolysis vapors produced in the reaction would allow for the separation of groups of compounds according to their normal boiling points $\left(T_{\mathrm{b}}\right)$ and the use or refining of each fraction separately and in a different way. As shown in Table 4, the $T_{\mathrm{b}}$ values of the surrogate organic compounds have been estimated using the QSPR (GCM) methods developed by Stein and Brown ${ }^{49}$ and Joback. ${ }^{46}$ Table 7 shows the estimated values of $T_{b}$.

The experimental and estimated $T_{\mathrm{b}}$ values for aldehydes, ketones, and acids differ by less than $6.3 \mathrm{~K}$, using either the method of Joback or that of Stein and Brown. The $T_{\mathrm{b}}$ values of furans, phenols, and methoxyphenols are better estimated with the Stein and Brown method, although in the case of phenols and methoxyphenols, the differences are large, around $20 \mathrm{~K}$. The largest deviations between experimental (see Table 5) and estimated (Table 7) $T_{\mathrm{b}}$ values are observed for syringaldehyde, 
Table 9. Estimated Values of Ideal Gas Phase Properties of the Compounds Included in the Surrogate Bio-oil and Differences with Experimental Values

\begin{tabular}{|c|c|c|c|c|c|c|}
\hline compound & $\begin{array}{l}C_{\mathrm{p}, \mathrm{G} 229 \mathrm{~K}}\left(\mathrm{~J} \mathrm{~mol} \mathrm{l}^{-1} \mathrm{~K}^{-1}\right), \\
\text { from Harrison and Seaton }\end{array}$ & $\begin{array}{c}\mathrm{C}_{\mathrm{p}, \mathrm{G}} 298 \mathrm{~K} \\
\left(\mathrm{~J} \mathrm{~mol}^{-1} \mathrm{~K}^{-1}\right)\end{array}$ & $\begin{array}{c}C_{\mathrm{p}, \mathrm{G} 2298 \mathrm{~K}} \\
\left(\mathrm{~J} \mathrm{~mol}^{-1} \mathrm{~K}^{-1}\right) \\
a b \text { initio }\end{array}$ & $\underset{\left(\mathrm{kJ} \text { mol }_{\mathrm{f}, \mathrm{G}}^{-1}\right)}{\Delta H_{\text {inio }}^{\circ}}$ & $\begin{array}{l}\Delta H_{\mathrm{fG}}^{\circ} \\
\left(\mathrm{kJ} \mathrm{mol}{ }^{-1}\right) \\
\text { from Joback }\end{array}$ & $\begin{array}{l}\Delta G_{\mathrm{fG}_{\mathrm{G}}}^{\circ} \\
\left(\mathrm{kJ} \mathrm{mol}{ }^{-1}\right) \\
\text { from Joback }\end{array}$ \\
\hline glycolaldehyde & 68.5 & 68.6 & 70.7 & -318.3 & -322.2 & -270.2 \\
\hline acetol & 88.9 & 87.7 & 90.3 & -373.9 & -369.8 & -291.2 \\
\hline 2-cyclopentenone & 95.6 & 76.0 & 88.0 & -93.3 & -145.5 & -57.1 \\
\hline 3-methyl-1,2-cyclopentanedione & 127.4 & 121.1 & 128.5 & -291.5 & -381.8 & -208.9 \\
\hline $\begin{array}{l}\text { aldehydes and ketones (family } \\
\text { average absolute difference) }\end{array}$ & $a$ & $a$ & & $a$ & $a$ & $a$ \\
\hline acetic acid & 68.5 & 65.4 & 64.8 & -431.9 & -434.6 & -377.7 \\
\hline propionic acid & 88.9 & 88.3 & 91.2 & -452.5 & -455.2 & -369.3 \\
\hline formic acid & 48.1 & 37.3 & 44.5 & -378.5 & -358.2 & -333.8 \\
\hline $\begin{array}{l}\text { acids (family average absolute } \\
\text { difference) }\end{array}$ & 3.7 & 5.2 & 1.3 & 1.2 & 7.7 & 1.9 \\
\hline furfural & 95.6 & 83.3 & 92.4 & -153.1 & -179.1 & -99.8 \\
\hline $2(5 H)$-furanone & 86.6 & 70.6 & 79.3 & -245.9 & -256.8 & -151.6 \\
\hline $\begin{array}{l}\text { furans (family average absolute } \\
\text { difference) }\end{array}$ & 2.5 & 14.8 & 5.7 & 6.5 & 14.2 & $a$ \\
\hline phenol & 104.6 & 80.8 & 102.1 & -88.3 & -96.4 & -32.9 \\
\hline guaiacol & 136.5 & 124.6 & 144.5 & -244.3 & -260.6 & -139.0 \\
\hline creosol & 156.9 & 153.3 & 165.8 & -277.0 & -292.7 & -140.2 \\
\hline 4-ethylguaiacol & 177.3 & 176.2 & 190.5 & -297.8 & -313.3 & -131.8 \\
\hline eugenol & 186.3 & 207.3 & 205.6 & -191.9 & -208.6 & -35.6 \\
\hline catechol & 116.0 & 102.7 & 122.4 & -266.5 & -273.6 & -187.4 \\
\hline syringol & 168.3 & 168.4 & 187.0 & -377.6 & -424.8 & -245.2 \\
\hline 4-methylcatechol & 136.5 & 131.5 & 144.1 & -299.3 & -305.7 & -188.6 \\
\hline vanillin & 156.9 & 157.5 & 170.2 & -376.0 & -378.2 & -239.7 \\
\hline syringaldehyde & 188.7 & 201.3 & 214.0 & -511.3 & -542.5 & -345.8 \\
\hline $\begin{array}{l}\text { phenols and methoxyphenols } \\
\text { (family average absolute } \\
\text { difference) }\end{array}$ & 2.7 & 19.9 & 1.7 & 5.1 & 12.0 & 0.3 \\
\hline levoglucosan & 173.0 & 168.8 & 176.4 & -819.2 & -815.1 & -508.6 \\
\hline cellobiosan & 341.1 & 349.3 & 377.1 & -1781.5 & -1686.3 & -1065.7 \\
\hline $\begin{array}{l}\text { anhydrosugars (family average } \\
\text { absolute difference) }\end{array}$ & 14.2 & 18.4 & 10.8 & 5.3 & 9.4 & $a$ \\
\hline HMM pyrolytic lignin & 1465.9 & 1580.3 & 1687.3 & -3048.5 & -3097.6 & -1316.1 \\
\hline LMM pyrolytic lignin & 594.9 & 668.2 & 684.4 & -1271.1 & -1447.9 & -750.9 \\
\hline humin & 694.8 & 952.1 & 827.1 & -1857.7 & -1798.2 & -1086.3 \\
\hline hybrid oligomer & 1491.8 & 1710.4 & 1712.2 & -5330.4 & -5093.3 & -3108.6 \\
\hline global average absolute difference & 4.9 & 13.9 & 3.7 & 4.4 & 11.1 & 1.4 \\
\hline
\end{tabular}

cellobiosan, and $2(5 H)$-furanone. Furthermore, some estimated $T_{\mathrm{b}}$ values are so high that the related compounds, such as oligomers, will thermally decompose prior to reaching their boiling temperature. However, these values are still useful because they are required as input data for the estimation of other properties. It is worth noting that the $T_{\mathrm{b}}$ values of some compounds, such as cellobiosan (see Table 7), are higher than the typical fast pyrolysis temperatures $(773 \mathrm{~K})$. This may support the hypothesis that anhydrosugars, such as cellobiosan or cellotriosan, are thermomechanically ejected during the pyrolysis reaction rather than vaporized, as some authors have suggested. ${ }^{87,88}$ The same observations can also be made for the four oligomers, whose estimated normal boiling points are between 1047.0 and $4126.4 \mathrm{~K}$. Such high boiling points suggest that these and other oligomers are produced during the pyrolysis reaction in the biomass via dehydration of cellulose in the liquid intermediate followed by thermal ejection to end up as humins ${ }^{89,90}$ rather than through secondary reactions in the 
Table 10. Adjustment Coefficients for $C_{\mathrm{p}, \mathrm{G}}$ versus the Temperature $(300-1500 \mathrm{~K})$ Obtained with the Joback Method ${ }^{a}$

\begin{tabular}{|c|c|c|c|c|}
\hline \multirow[b]{2}{*}{ compound } & \multicolumn{4}{|c|}{ Joback method } \\
\hline & A & B & $\mathrm{C}$ & $\mathrm{D}$ \\
\hline glycolaldehyde & 4.2230 & $4.8170 \times 10^{-2}$ & $-2.6100 \times 10^{-5}$ & $4.8500 \times 10^{-9}$ \\
\hline acetol & 3.0530 & $7.0270 \times 10^{-2}$ & $-3.6120 \times 10^{-5}$ & $6.0340 \times 10^{-9}$ \\
\hline 2-cyclopentenone & -5.7000 & $9.8400 \times 10^{-2}$ & $-4.1702 \times 10^{-5}$ & $-6.6780 \times 10^{-8}$ \\
\hline 3-methyl-1,2-cyclopentanedione & 2.3400 & $8.7870 \times 10^{-2}$ & $1.3680 \times 10^{-5}$ & $-3.0380 \times 10^{-8}$ \\
\hline acetic acid & 1.3500 & $5.8270 \times 10^{-2}$ & $-3.7600 \times 10^{-5}$ & $9.7000 \times 10^{-9}$ \\
\hline propionic acid & 1.1330 & $8.0970 \times 10^{-2}$ & $-5.0600 \times 10^{-5}$ & $1.2550 \times 10^{-8}$ \\
\hline formic acid & -3.3100 & $6.0200 \times 10^{-2}$ & $-7.4200 \times 10^{-5}$ & $3.2800 \times 10^{-8}$ \\
\hline furfural & -2.2700 & $1.0427 \times 10^{-1}$ & $-7.5873 \times 10^{-5}$ & $-8.1420 \times 10^{-8}$ \\
\hline $2(5 H)$-furanone & -1.3400 & $7.5000 \times 10^{-2}$ & $-2.5392 \times 10^{-5}$ & $-7.1710 \times 10^{-8}$ \\
\hline phenol & $-1.4252 \times 10^{1}$ & $1.6930 \times 10^{-1}$ & $-1.5676 \times 10^{-4}$ & $-1.1280 \times 10^{-7}$ \\
\hline guaiacol & -4.9520 & $1.6277 \times 10^{-1}$ & $-1.2706 \times 10^{-4}$ & $-9.4800 \times 10^{-8}$ \\
\hline creosol & -1.7520 & $1.7134 \times 10^{-1}$ & $-1.2387 \times 10^{-4}$ & $-6.3700 \times 10^{-8}$ \\
\hline 4-ethylguaiacol & -1.9690 & $1.9404 \times 10^{-1}$ & $-1.3687 \times 10^{-4}$ & $-6.0850 \times 10^{-8}$ \\
\hline eugenol & -2.8990 & $1.2987 \times 10^{-1}$ & $2.1353 \times 10^{-4}$ & $-1.9875 \times 10^{-7}$ \\
\hline catechol & $-1.6384 \times 10^{1}$ & $2.0640 \times 10^{-1}$ & $-2.1776 \times 10^{-4}$ & $-4.6800 \times 10^{-8}$ \\
\hline syringol & 4.3480 & $1.5624 \times 10^{-1}$ & $-9.7373 \times 10^{-5}$ & $-7.6800 \times 10^{-8}$ \\
\hline 4-methylcatechol & $-1.3184 \times 10^{1}$ & $2.1497 \times 10^{-1}$ & $-2.1457 \times 10^{-4}$ & $-1.5700 \times 10^{-8}$ \\
\hline vanillin & $9.5800 \times 10^{-1}$ & $1.6524 \times 10^{-1}$ & $-1.2237 \times 10^{-4}$ & $-6.4200 \times 10^{-8}$ \\
\hline syringaldehyde & $1.0258 \times 10^{1}$ & $1.5871 \times 10^{-1}$ & $-9.2682 \times 10^{-5}$ & $-4.6200 \times 10^{-8}$ \\
\hline levoglucosan & $-1.0770 \times 10^{1}$ & $2.0790 \times 10^{-1}$ & $-1.3141 \times 10^{-4}$ & $3.0170 \times 10^{-8}$ \\
\hline cellobiosan & -8.0770 & $3.5600 \times 10^{-1}$ & $-1.6841 \times 10^{-4}$ & $1.4400 \times 10^{-8}$ \\
\hline HMM pyrolytic lignin & $3.1636 \times 10^{1}$ & 1.4488 & $-8.6866 \times 10^{-4}$ & $-3.2776 \times 10^{-7}$ \\
\hline LMM pyrolytic lignin & $2.5319 \times 10^{1}$ & $4.9751 \times 10^{-1}$ & $-2.0612 \times 10^{-4}$ & $1.6495 \times 10^{-7}$ \\
\hline humin & -6.4590 & $7.8977 \times 10^{-1}$ & $-5.8717 \times 10^{-4}$ & $1.9146 \times 10^{-6}$ \\
\hline hybrid oligomer & $1.3362 \times 10^{1}$ & 1.5294 & $-8.8978 \times 10^{-4}$ & $6.9976 \times 10^{-7}$ \\
\hline
\end{tabular}

bio-oil. Similarly, lignin or phenolic oligomers ${ }^{89,91}$ detected in the bio-oil could originate from thermal or thermomechanical ejection of the bubbling pyrolytic lignin, which is a presumed liquid intermediate of thermally degrading biomass. If true, this may represent a major challenge for the development of microkinetic models. ${ }^{92}$ Lastly, as shown in Table 4 and explained in the Results in connection with the critical properties, estimated normal boiling points are required for the calculation of the $T_{\mathrm{c}}$ data according to Lydersen et al. (eq $\mathrm{S} 1$ of the Supporting Information) and Joback (eq S2 of the Supporting Information), $\Delta H_{\text {vap, } T_{\mathrm{b}}}$ according to Riedel (eq S10 of the Supporting Information) and $\Delta H_{\text {vap,298 } \mathrm{K}}$ according to the Watson equation (eq S12 of the Supporting Information) and according to TMD_VAP_ENTH (eq S13 of the Supporting Information).

3.2.1.3. Enthalpy of Vaporization. The enthalpies of vaporization or condensation are useful to calculate energy balances in condensation/distillation processes applied to the bio-oil and also to calculate the liquid enthalpy of formation of the compounds from their gas enthalpy of formation. Table 4 shows the methods used for the estimation of the enthalpy of vaporization corresponding to $T_{\mathrm{b}}$ and $298.15 \mathrm{~K}\left(\Delta H_{\mathrm{vap}, T_{\mathrm{b}}}\right.$ and $\left.\Delta H_{\text {vap }, 298 \mathrm{~K}}\right)$.

The estimated values for $\Delta H_{\text {vap, } T_{\mathrm{b}}}$ and $\Delta H_{\mathrm{vap}, 298 \mathrm{~K}}$ can be observed in Table 7. Both, the methods of Joback and Riedel provide good estimates of $\Delta H_{\mathrm{vap}, T_{\mathrm{b}}}$, for almost all of the component families for which experimental data are available, and the differences are between 0.7 and $6.0 \mathrm{~kJ} \mathrm{~mol}^{-1}$. The $\Delta H_{\text {vap }, T_{\mathrm{b}}}$ value for humin determined with the Riedel method is rather small and likely more accurate than the estimate using Joback parameters.

The estimation methods used for $\Delta H_{\mathrm{vap}, 298 \mathrm{~K}}$ (Watson and TMD_VAP_ENTH) differ from the experimental values on average by less than $10 \mathrm{~kJ} \mathrm{~mol}^{-1}$ for acids, phenols, and methoxyphenols, but for furans, larger deviations were observed (around $16 \mathrm{~kJ} \mathrm{~mol}^{-1}$ ). The performance of both methods is quite similar, except for phenols and methoxyphenols, for which the Watson method leads to better estimates. Among the four oligomer molecules, it was only possible to estimate $\Delta H_{\text {vap,298 } \mathrm{K}}$ with both methods for LMM pyrolytic lignin and humin. The results of the TMD_VAP_ENTH calculation (eq S13 of the Supporting Information) are significantly larger than those with the Watson method (eq S12 of the Supporting Information). The estimated $\Delta H_{\mathrm{vap}, 298 \mathrm{~K}}$ values according to TMD_VAP_ENTH for the HMM pyrolytic lignin, humin, and hybrid oligomer molecules seem very high when compared to that of water $\left(44.29 \mathrm{~kJ} \mathrm{~mol}^{-1}\right)$, with close to four hydrogen bonds per water molecule, or even with those of some metals, such as $\mathrm{Al}\left(294 \mathrm{~kJ} \mathrm{~mol}^{-1}\right), \mathrm{Cu}(305$ $\left.\mathrm{kJ} \mathrm{mol}^{-1}\right)$, or $\mathrm{Fe}\left(354 \mathrm{~kJ} \mathrm{~mol}^{-1}\right) .{ }^{93}$ For this reason, the $\Delta H_{\text {vap,298 K }}$ values obtained with the TMD_VAP_ENTH calculation for the three aforementioned oligomeric molecules should be used with caution because they may be overestimated. In addition, as previously mentioned, the high normal boiling points of the oligomeric compounds would cause these compounds to thermally decompose before evaporation.

3.2.1.4. Vapor Pressure Curves of Bio-oil Compounds. One of the separation processes considered in a biorefinery scheme is distillation, mainly at ambient or vacuum conditions. Distillation of the whole fast pyrolysis bio-oil and partially 
Table 11. Adjustment Coefficients for $C_{\mathrm{p}, \mathrm{G}}$ versus the Temperature (220-1500 K) for HMM Pyrolytic Lignin, Humin, and Hybrid Oligomer and $(298-2500 \mathrm{~K})$ for the Rest of the Compounds Obtained from the Polynomial Fitting of $A b$ Initio Calculated $C_{\mathrm{p}, \mathrm{G}}$ Values versus the Temperature ${ }^{a}$

\begin{tabular}{|c|c|c|c|c|c|c|}
\hline \multirow[b]{2}{*}{ compound } & \multicolumn{6}{|c|}{$a b$ initio calculations } \\
\hline & A & B & $\mathrm{C}$ & $\mathrm{D}$ & $\mathrm{E}$ & $R^{2}$ \\
\hline glycolaldehyde & -6.8223 & $3.2886 \times 10^{-1}$ & $-2.6070 \times 10^{-4}$ & $9.6134 \times 10^{-8}$ & $-1.3364 \times 10^{-11}$ & 0.9997 \\
\hline acetol & -6.7996 & $3.9910 \times 10^{-1}$ & $-2.8106 \times 10^{-4}$ & $9.4467 \times 10^{-8}$ & $-1.2231 \times 10^{-11}$ & 0.9999 \\
\hline 2-cyclopentenone & $-2.3842 \times 10^{1}$ & $4.6483 \times 10^{-1}$ & $-3.2656 \times 10^{-4}$ & $1.1216 \times 10^{-7}$ & $-1.4986 \times 10^{-11}$ & 0.9999 \\
\hline 3-methyl-1,2-cyclopentanedione & $-1.0192 \times 10^{1}$ & $5.7315 \times 10^{-1}$ & $-3.9240 \times 10^{-4}$ & $1.3207 \times 10^{-7}$ & $-1.7389 \times 10^{-11}$ & 0.9999 \\
\hline acetic acid & 6.8120 & $2.3735 \times 10^{-1}$ & $-1.5595 \times 10^{-4}$ & $5.1304 \times 10^{-8}$ & $-6.6732 \times 10^{-12}$ & 0.9999 \\
\hline propionic acid & $1.6563 \times 10^{1}$ & $2.9774 \times 10^{-1}$ & $-1.7798 \times 10^{-4}$ & $5.3374 \times 10^{-8}$ & $-6.4048 \times 10^{-12}$ & 0.9999 \\
\hline formic acid & $1.1179 \times 10^{1}$ & $1.3639 \times 10^{-1}$ & $-9.0935 \times 10^{-5}$ & $3.0134 \times 10^{-8}$ & $-3.9266 \times 10^{-12}$ & 0.9999 \\
\hline furfural & $-1.2890 \times 10^{1}$ & $4.4415 \times 10^{-1}$ & $-3.3082 \times 10^{-4}$ & $1.1811 \times 10^{-7}$ & $-1.6180 \times 10^{-11}$ & 0.9998 \\
\hline $2(5 H)$-furanone & $-1.5470 \times 10^{1}$ & $3.9876 \times 10^{-1}$ & $-2.9276 \times 10^{-4}$ & $1.0364 \times 10^{-7}$ & $-1.4130 \times 10^{-11}$ & 0.9998 \\
\hline phenol & $-2.3230 \times 10^{1}$ & $5.3299 \times 10^{-1}$ & $-4.0349 \times 10^{-4}$ & $1.4713 \times 10^{-7}$ & $-2.0548 \times 10^{-11}$ & 0.9997 \\
\hline guaiacol & $-1.5658 \times 10^{1}$ & $6.7281 \times 10^{-1}$ & $-4.9761 \times 10^{-4}$ & $1.7589 \times 10^{-7}$ & $-2.3844 \times 10^{-11}$ & 0.9999 \\
\hline creosol & $-1.5213 \times 10^{1}$ & $7.5304 \times 10^{-1}$ & $-5.3762 \times 10^{-4}$ & $1.8535 \times 10^{-7}$ & $-2.4695 \times 10^{-11}$ & 0.9999 \\
\hline 4-ethylguaiacol & $-1.3210 \times 10^{1}$ & $8.4438 \times 10^{-1}$ & $-5.9490 \times 10^{-4}$ & $2.0333 \times 10^{-7}$ & $-2.6939 \times 10^{-11}$ & 0.9999 \\
\hline eugenol & -5.4252 & $8.7756 \times 10^{-1}$ & $-6.2257 \times 10^{-4}$ & $2.1418 \times 10^{-7}$ & $-2.8546 \times 10^{-11}$ & 0.9999 \\
\hline catechol & $-1.7041 \times 10^{1}$ & $5.9936 \times 10^{-1}$ & $-4.7632 \times 10^{-4}$ & $1.7838 \times 10^{-7}$ & $-2.5253 \times 10^{-11}$ & 0.9996 \\
\hline syringol & $2.3902 \times 10^{1}$ & $6.6671 \times 10^{-1}$ & $-4.4512 \times 10^{-4}$ & $1.4618 \times 10^{-7}$ & $-1.8822 \times 10^{-11}$ & 0.9999 \\
\hline 4-methylcatechol & $-1.4987 \times 10^{1}$ & $6.7263 \times 10^{-1}$ & $-5.0729 \times 10^{-4}$ & $1.8335 \times 10^{-7}$ & $-2.5349 \times 10^{-11}$ & 0.9998 \\
\hline vanillin & -5.7563 & $7.3466 \times 10^{-1}$ & $-5.3177 \times 10^{-4}$ & $1.8371 \times 10^{-7}$ & $-2.4422 \times 10^{-11}$ & 0.9999 \\
\hline syringaldehyde & $3.1528 \times 10^{1}$ & $7.4706 \times 10^{-1}$ & $-5.0194 \times 10^{-4}$ & $1.6444 \times 10^{-7}$ & $-2.1062 \times 10^{-11}$ & 0.9999 \\
\hline levoglucosan & $-3.5604 \times 10^{1}$ & $9.0670 \times 10^{-1}$ & $-7.0534 \times 10^{-4}$ & $2.6081 \times 10^{-7}$ & $-3.6676 \times 10^{-11}$ & 0.9996 \\
\hline cellobiosan & $-7.6684 \times 10^{1}$ & 1.9543 & $-1.5742 \times 10^{-3}$ & $5.9138 \times 10^{-7}$ & $-8.3687 \times 10^{-11}$ & 0.9996 \\
\hline HMM pyrolytic lignin & $-2.4143 \times 10^{2}$ & 8.2685 & $-6.7693 \times 10^{-3}$ & $2.7824 \times 10^{-6}$ & $-4.5416 \times 10^{-10}$ & 0.9999 \\
\hline LMM pyrolytic lignin & $-5.3223 \times 10^{1}$ & 3.1164 & $-2.3410 \times 10^{-3}$ & $8.3606 \times 10^{-7}$ & $-1.1427 \times 10^{-10}$ & 0.9998 \\
\hline humin & $-1.0842 \times 10^{2}$ & 4.1245 & $-3.7770 \times 10^{-3}$ & $1.7512 \times 10^{-6}$ & $-3.2453 \times 10^{-10}$ & 0.9999 \\
\hline hybrid oligomer & $-2.8310 \times 10^{2}$ & 8.6212 & $-7.2978 \times 10^{-3}$ & $3.1323 \times 10^{-6}$ & $-5.3792 \times 10^{-10}$ & 0.9999 \\
\hline $\mathrm{C}, \mathrm{G}_{\mathrm{G}}\left(\mathrm{J} \mathrm{mol}^{-1} \mathrm{~K}^{-1}\right)=A+B$ & ${ }^{2}+D T^{3}+E T$ & K). & & & & \\
\hline
\end{tabular}

deoxygenated bio-oil has been studied theoretically and experimentally by various authors, aiming to separate target bio-oil families of compounds, ${ }^{21,94,95}$ to measure the distillation curve, ${ }^{96}$ or to develop a thermodynamic model of bio-oil vapor-liquid equilibrium (VLE) curves. ${ }^{22}$ As shown in Table 4, vapor pressure curves have been estimated according to two methods, the Clausius-Clapeyron equation and the QPPR method developed by Riedel. ${ }^{53}$ Moreover, Antoine coefficients that describe the relation between the vapor pressure and temperature for some of the compounds included in the surrogate bio-oil composition were found in the literature $^{97}$ (see Table S6 in section S.4 of the Supporting Information). The vapor pressure curves built with these Antoine coefficients have been used to choose the most appropriate method among those used for the estimation of the vapor pressure curves of the rest of the compounds. As observed in Figure S3 of the Supporting Information, the Riedel method provides slightly better estimations for the vapor pressure curves than the Clausius-Clapeyron equation.

Figure 1 shows the estimated vapor pressure curves according to Riedel ${ }^{53}$ for the surrogate bio-oil compounds belonging to the lightest chemical families: aldehydes, ketones, acids, furans, phenols, and methoxyphenols. In a biorefinery scheme, distillation could be applied to the bio-oil fraction separated by fractionation as water soluble and diethyl ethermethylene dichloride soluble to separate the lighter compounds present in the bio-oil. The water-soluble and diethyl ether-methylene dichloride-soluble fraction would concentrate compounds belonging to the aforementioned lightest chemical families. It would not contain other bio-oil components, such as water, sugars, or pyrolytic lignin, which could make distillation technically challenging. ${ }^{96}$ As observed in Figure 1, the vapor pressures of phenols are, generally speaking, lower than those of the other compounds, except 3methyl-1,2-cyclopentanedione, at any of the temperatures. That is to say, at a certain pressure, the boiling temperatures of phenols are the highest. For the same pressure, aldehydes, ketones, acids, and furans present lower boiling temperatures in the whole interval. On the basis of these results, it seems that the separation of bio-oil compounds by chemical families via distillation is feasible. With regard to the separation of specific compounds via distillation, the vapor pressure curves of some compounds, such as formic acid, acetic acid, furfural, phenol, or vanillin, differ significantly from those of the others, although one should bear in mind that real bio-oil contains significantly more compounds than this surrogate bio-oil. Table S7 of the Supporting Information shows the fit of the vapor pressure curves obtained according to the Riedel method as a function of the temperature for the compounds shown in Figure 1.

3.2.1.5. Normal Melting Point and Enthalpy of Fusion. 3.2.1.5.1. Normal Melting Points. Normal melting or solidification points $\left(T_{\mathrm{m}}\right)$ can be useful to explore the possibility of isolating compounds by crystallization, especially sugars and anhydrosugars, from the bio-oil matrix, as already been proposed and developed experimentally for levoglucosan. ${ }^{98}$ Then, the enthalpy of fusion or solidification at the melting point $\left(\Delta H_{\text {fus, } T_{\mathrm{m}}}\right)$ would be required to determine the cooling requirements for separating these compounds by crystalliza- 
Table 12. Estimated Values of Condensed-Phase Properties of the Compounds Included in the Surrogate Bio-oil and Differences with Experimental Values

\begin{tabular}{|c|c|c|c|c|}
\hline compound & $\begin{array}{l}C_{\mathrm{p}, \mathrm{L}}\left(\mathrm{J} \mathrm{mol}^{-1} \mathrm{~K}^{-1}\right) \text {, from } \\
\text { Chueh and Swanson }\end{array}$ & $\begin{array}{c}C_{\mathrm{p}, \mathrm{S}}\left(\mathrm{J} \mathrm{mol}^{-1} \mathrm{~K}^{-1}\right) \text {, from Hurst } \\
\text { and Harrison }\end{array}$ & $\begin{array}{l}\Delta H_{\mathrm{f}, \mathrm{L}}^{\circ}\left(\mathrm{kJ} \mathrm{mol}{ }^{-1}\right) \\
\text { TMD_LQ_ENTH }\end{array}$ & $\begin{array}{l}\Delta H_{\mathrm{fLL}}^{\circ}\left(\mathrm{kJ} \mathrm{mol}{ }^{-1}\right), \\
\text { ENTH_BAL }\end{array}$ \\
\hline glycolaldehyde & 126.2 & 78.9 & -388.3 & -375.9 \\
\hline acetol & 163.0 & 104.9 & -415.9 & -398.4 \\
\hline 2-cyclopentenone & 149.2 & 113.2 & -130.0 & -181.4 \\
\hline 3-methyl-1.2-cyclopentanedione & 213.1 & 152.7 & -338.6 & -369.3 \\
\hline $\begin{array}{l}\text { aldehydes and ketones (family average } \\
\text { absolute difference) }\end{array}$ & $a$ & $a$ & $a$ & $a$ \\
\hline acetic acid & 116.7 & 78.9 & -482.6 & -375.9 \\
\hline propionic acid & 147.1 & 104.9 & -510.1 & -398.4 \\
\hline formic acid & 94.6 & 52.9 & -424.9 & -353.4 \\
\hline acids (family average absolute difference) & 5.6 & $a$ & 0.8 & 97.5 \\
\hline furfural & 185.6 & 111.5 & -201.6 & -298.5 \\
\hline $2(5 H)$-furanone & 158.4 & 100.6 & -312.8 & -324.3 \\
\hline furans (family average absolute difference) & 22.4 & $a$ & 0.03 & 54.2 \\
\hline phenol & 167.8 & 124.1 & -154.2 & -155.6 \\
\hline guaiacol & 229.7 & 163.6 & -308.7 & -343.5 \\
\hline creosol & 256.5 & 189.6 & -362.8 & -366.0 \\
\hline 4-ethylguaiacol & 297.3 & 215.6 & -369.7 & -388.5 \\
\hline eugenol & 322.4 & 226.5 & -258.2 & -362.7 \\
\hline catechol & 202.5 & 137.5 & -339.4 & -321.0 \\
\hline syringol & 291.6 & 203.0 & -454.6 & -531.5 \\
\hline 4-methylcatechol & 229.3 & 163.6 & -376.5 & -343.5 \\
\hline vanillin & 291.5 & 187.9 & -442.9 & -483.2 \\
\hline syringaldehyde & 353.4 & 227.3 & -596.0 & -671.1 \\
\hline $\begin{array}{l}\text { phenols and methoxyphenols (family average } \\
\text { absolute difference) }\end{array}$ & 20.8 & 3.0 & 0.00 & 19.0 \\
\hline levoglucosan & 361.5 & 208.04 & -963.3 & -913.9 \\
\hline cellobiosan & 712.6 & 416.08 & -2044.3 & -1827.8 \\
\hline $\begin{array}{l}\text { anhydrosugars (family average absolute } \\
\text { difference) }\end{array}$ & $a$ & $a$ & $a$ & $a$ \\
\hline HMM pyrolytic lignin & 2638.6 & 1807.3 & -5010.3 & -3930.2 \\
\hline LMM pyrolytic lignin & 1143.8 & 731.4 & -1525.1 & -1867.0 \\
\hline humin & 1592.9 & 848.7 & -2150.3 & -2491.2 \\
\hline hybrid oligomer & 2999.3 & 1838.5 & -8254.0 & -5799.5 \\
\hline global average absolute difference & 13.6 & 3.0 & 0.4 & 62.7 \\
\hline
\end{tabular}

tion. Table 4 shows the two QSPR methods used for their estimation. The estimated values for $T_{\mathrm{m}}$ and $\Delta H_{\text {fus, } T_{\mathrm{m}}}$ can be found in Table 8.

The $T_{\mathrm{m}}$ values estimated with the Joback method are in quite good agreement with the experimental values available, except for phenols and methoxyphenols, whose $T_{\mathrm{m}}$ values are more accurately predicted by the method developed by PérezPonce (see Table 8). The Joback method estimates very accurately $\Delta H_{\text {fus, } T_{\mathrm{m}}}$, with average absolute deviations from the experimental values being less than $3 \mathrm{~kJ} \mathrm{~mol}^{-1}$. The estimated values of $T_{\mathrm{m}}$ for the four oligomeric compounds seem to be too high, possibly because the two methods were developed for smaller molecules. Therefore, these values should be treated carefully.

3.2.2. Ideal Gas Properties of Individual Compounds. 3.2.2.1. Gas Heat Capacity, Enthalpy of Formation, and Gibbs Free Energy. The gas heat capacity and enthalpy of formation are required to calculate the energy balance of the pyrolysis reaction, while the Gibbs free energy of the compounds is very useful to analyze the spontaneity of a reaction. The experimental values available in the literature for these properties are shown in Table 5. Table 4 shows the methods used for their estimation or calculation. 
Table 13. Hansen Solubility Parameters of the Surrogate Bio-oil Compounds Estimated According to the Hansen and Stefanis and Panayiotou Group Contribution Methods

\begin{tabular}{|c|c|c|c|c|c|c|c|c|}
\hline \multirow[b]{2}{*}{ compound } & \multicolumn{4}{|c|}{ Hansen first-order group contribution method } & \multicolumn{4}{|c|}{ Stefanis and Panayiotou first-order group contribution method } \\
\hline & $\delta_{\mathrm{d}}\left(\mathrm{MPa}^{(1 / 2)}\right)$ & $\delta_{\mathrm{p}}\left(\mathrm{MPa}^{(1 / 2)}\right)$ & $\delta_{\mathrm{hb}}\left(\mathrm{MPa}^{(1 / 2)}\right)$ & $\delta_{\mathrm{T}}\left(\mathrm{MPa}^{(1 / 2)}\right)^{a}$ & $\delta_{\mathrm{d}}\left(\mathrm{MPa}^{(1 / 2)}\right)$ & $\delta_{\mathrm{p}}\left(\mathrm{MPa}^{(1 / 2)}\right)$ & $\delta_{\mathrm{hb}}\left(\mathrm{MPa}^{(1 / 2)}\right)$ & $\delta_{\mathrm{T}}\left(\mathrm{MPa}^{(1 / 2)}\right)^{a}$ \\
\hline glycolaldehyde & 18.2 & 15.4 & 21.9 & 32.4 & 16.5 & 11.7 & 14.9 & 25.2 \\
\hline acetol & 16.0 & 7.4 & 18.0 & 25.2 & 16.6 & 10.5 & 13.5 & 23.8 \\
\hline 2-cyclopentenone & 19.7 & 7.9 & 8.3 & 22.7 & 18.0 & 10.5 & 7.0 & 21.9 \\
\hline 3-methyl-1,2-cyclopentanediene & 20.9 & 9.8 & 8.8 & 24.7 & 17.2 & 10.6 & 7.9 & 21.7 \\
\hline acetic acid & 17.4 & 5.8 & 13.6 & 22.8 & 16.1 & 6.6 & 10.9 & 20.5 \\
\hline propionic acid & 17.4 & 5.2 & 12.1 & 21.8 & 16.0 & 6.3 & 10.5 & 20.2 \\
\hline formic acid & 18.5 & 18.8 & 26.7 & 37.5 & 16.6 & 12.0 & 15.3 & 25.6 \\
\hline furfural & 17.2 & 15.8 & 12.1 & 26.3 & 17.5 & 13.0 & 6.2 & 22.7 \\
\hline $2(5 H)$-furanone & 19.6 & 10.9 & 10.8 & 24.9 & 17.2 & 8.0 & 9.6 & 21.2 \\
\hline phenol & 22.0 & 6.6 & 15.5 & 27.7 & 18.4 & 5.8 & 12.8 & 23.1 \\
\hline guaiacol & 19.4 & 8.2 & 17.9 & 27.6 & 18.6 & 7.1 & 13.4 & 24.0 \\
\hline creosol & 19.1 & 7.7 & 16.6 & 26.5 & 18.7 & 7.1 & 12.7 & 23.6 \\
\hline 4-ethylguaiacol & 18.9 & 7.2 & 15.5 & 25.5 & 18.2 & 6.7 & 12.9 & 23.2 \\
\hline eugenol & 18.8 & 7.0 & 15.4 & 25.3 & 18.1 & 6.3 & 12.4 & 22.8 \\
\hline catechol & 17.6 & 10.1 & 25.1 & 32.3 & 18.8 & 7.4 & 20.2 & 28.6 \\
\hline syringol & 18.8 & 8.6 & 17.7 & 27.2 & 18.7 & 8.5 & 14.0 & 24.8 \\
\hline 4-methylcatechol & 17.6 & 9.3 & 22.8 & 30.3 & 18.9 & 7.4 & 19.5 & 28.1 \\
\hline vanillin & 18.7 & 13.1 & 17.7 & 28.9 & 18.9 & 11.8 & 14.0 & 26.3 \\
\hline syringaldehyde & 18.2 & 12.8 & 17.5 & 28.3 & 19.0 & 13.1 & 14.6 & 27.3 \\
\hline levoglucosan & 28.4 & 19.7 & 35.7 & 49.7 & 20.0 & 15.3 & 29.0 & 38.4 \\
\hline cellobiosan & 21.4 & 15.9 & 32.8 & 42.3 & 22.6 & 24.2 & 50.9 & 60.7 \\
\hline HMM pyrolytic lignin & 22.6 & 9.8 & 18.5 & 30.8 & 44.1 & 39.1 & 42.1 & 72.4 \\
\hline LMM pyrolytic lignin & 21.3 & 9.6 & 19.8 & 30.6 & 20.1 & 12.6 & 25.7 & 38.3 \\
\hline humin & 15.9 & 6.7 & 15.6 & 23.3 & 21.4 & 30.1 & 32.8 & 49.4 \\
\hline \multirow[t]{3}{*}{ hybrid oligomer } & 23.3 & 11.1 & 24.2 & 35.4 & 38.5 & 65.6 & 110.4 & 134.0 \\
\hline & \multicolumn{8}{|c|}{ experimental values } \\
\hline & \multicolumn{2}{|c|}{$\delta_{\mathrm{d}}\left(\mathrm{MPa}^{(1 / 2)}\right)$} & \multicolumn{2}{|c|}{$\delta_{\mathrm{p}}\left(\mathrm{MPa}^{(1 / 2)}\right)$} & \multicolumn{2}{|c|}{$\delta_{\mathrm{hb}}\left(\mathrm{MPa}^{(1 / 2)}\right)$} & \multicolumn{2}{|c|}{$\delta_{\mathrm{T}}\left(\mathrm{MPa}^{(1 / 2)}\right)^{a}$} \\
\hline acetic acid & \multicolumn{2}{|c|}{14.5} & \multicolumn{2}{|l|}{8} & \multicolumn{2}{|c|}{13.5} & \multicolumn{2}{|c|}{21.4} \\
\hline formic acid & \multicolumn{2}{|c|}{14.3} & \multicolumn{2}{|c|}{11.9} & \multicolumn{2}{|c|}{16.6} & \multicolumn{2}{|c|}{24.9} \\
\hline
\end{tabular}

Table 9 shows the estimated values for the gas heat capacity at $298 \mathrm{~K}$, the gas enthalpy of formation, and the Gibbs free energy $\left(C_{\mathrm{p}, \mathrm{G} 298 \mathrm{~K},} \Delta H_{\mathrm{f}, \mathrm{G}}^{\circ}\right.$, and $\left.\Delta G_{\mathrm{f}, \mathrm{G}}^{\circ}\right)$ of the compounds included in the proposed surrogate for bio-oil.

3.2.2.2. Gas-Phase Heat Capacity at a Constant Pressure at $298 \mathrm{~K}$. The gas heat capacities at $298 \mathrm{~K}$ have been estimated with two different methods, the Joback method ${ }^{46}$ and the Harrison and Seaton method, ${ }^{54}$ apart from their determination by means of $a b$ initio calculations. Of the two estimation methods, the Harrison and Seaton method resulted in $C_{\mathrm{p}, \mathrm{G} 298 \mathrm{~K}}$ values closer to the experimental values than the Joback method for all of the chemical families included in the proposed surrogate bio-oil (see Table 9). Taking into account the absolute differences shown by the estimated $C_{\mathrm{p}, \mathrm{G}}$ values according to Harrison and Seaton, it can be said that this method is appropriate for estimating this property for the compounds typically found in bio-oil and especially for acids and phenols. On the other hand, $C_{\mathrm{p}, \mathrm{G}} 298 \mathrm{~K}$ values obtained by means of $a b$ initio calculations provide the closest values to the experimental values, except for furans.

3.2.2.3. Gas-Phase Heat Capacity at a Constant Pressure as Function of the Temperature. Gas heat capacities as a function of the temperature have been determined with the Joback method ${ }^{46}$ and by $a b$ initio calculations. Tables 10 and 11 show the coefficients of adjustment for the polynomial expression of $C_{\mathrm{p}, \mathrm{G}}$ versus the temperature obtained from the Joback estimation method and from the adjustment of the $C_{\mathrm{p}, \mathrm{G}}$ values determined at different temperatures by the $a b$ initio calculations. These $C_{\mathrm{p}, \mathrm{G}}$ values can be useful to accomplish the energy balance of many processes, such as the pyrolysis reaction itself, condensation, or distillation.

The $C_{\mathrm{pG}}(T)$ curves obtained with the ab initio calculations approach reach an asymptotic value for $C_{\mathrm{pG}}$ at high temperatures for all of the compounds, as theoretically should occur. However, the $C_{\mathrm{pG}}(T)$ curves provided by the Joback method only approach asymptotically the high-temperature limit for glycolaldehyde, acetol, 3-methyl-1,2-cyclopentanedione, acetic acid, propionic acid, levoglucosan, and cellobiosan. For this reason, it would be recommendable to determine the calculation of the $C_{\mathrm{pG}}(T)$ curves with the $a b$ initio method rather than the Joback method, especially for furans, phenols, methoxy phenols, and the four oligomers.

3.2.2.4. Gas-Phase Standard Enthalpy of Formation and Standard Gibbs Free Energy. In comparison to the available experimental data, $a b$ initio quantum mechanical calculations at the CBS-QB3 level of theory yield more accurate enthalpies of formation $\Delta H_{\mathrm{f}, \mathrm{G}}^{\circ}$ than the Joback group additivity-based method (see Table 9). The CBS-QB3 results differ from the experimental values by less than $7 \mathrm{~kJ} \mathrm{~mol}^{-1}$. The Joback method provides estimates that are close to the CBS-QB3 calculations, being computationally much less expensive and far less time-consuming. Even for the four oligomers, whose chemical structures are complex, the Joback method performs reasonably well. 


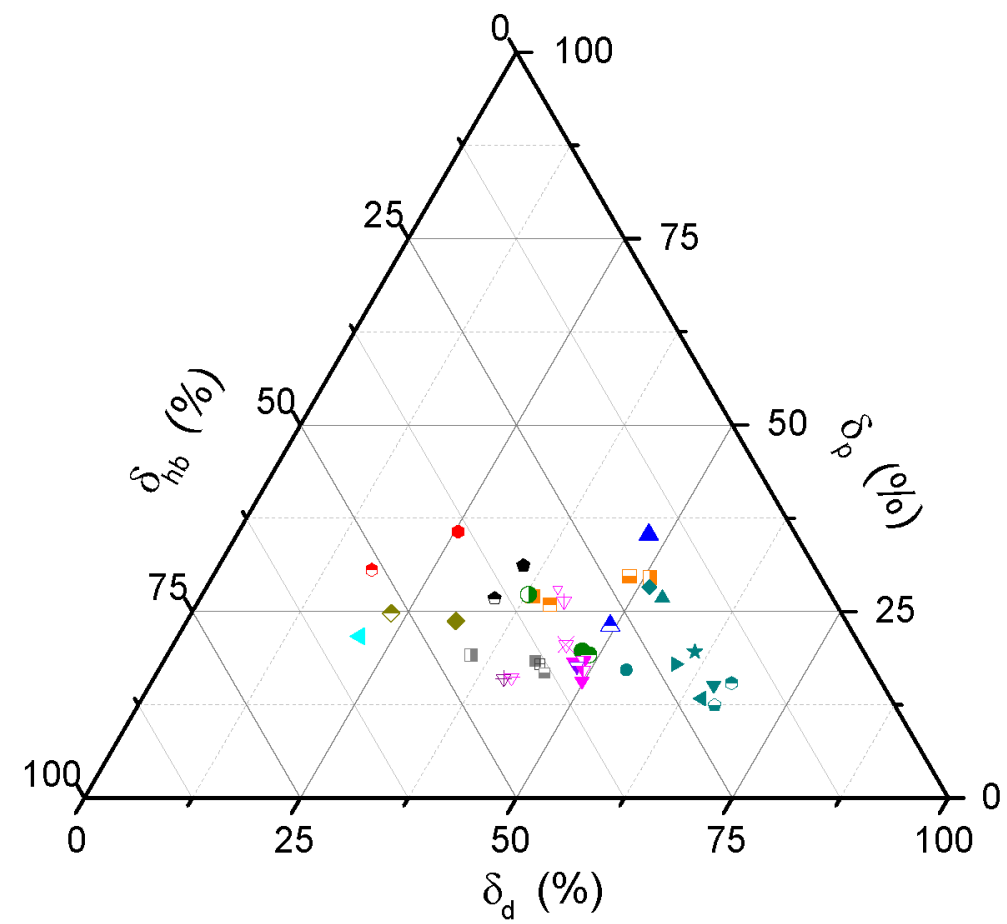

\section{Surrogate compounds:}

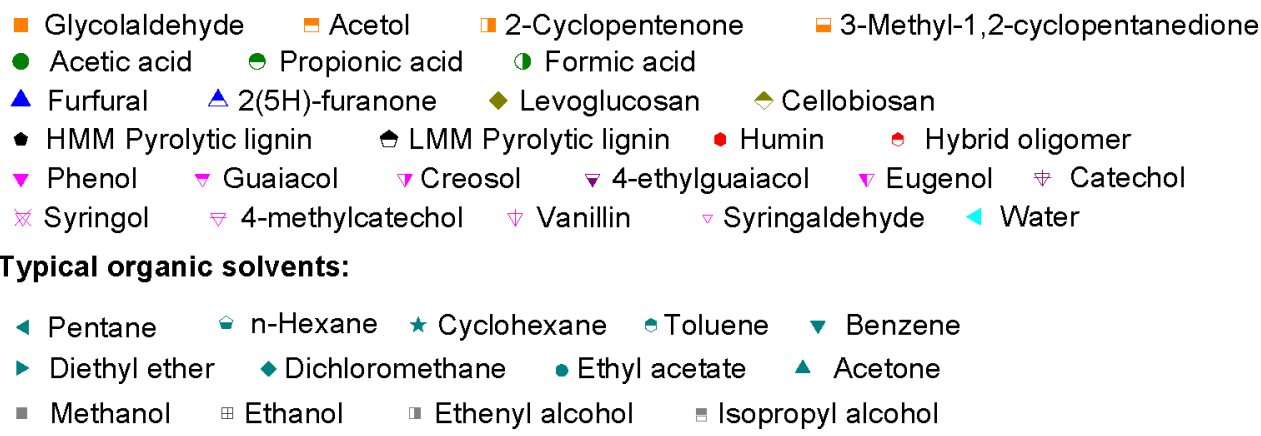

Figure 2. Solubility parameters of the surrogate compounds and some solvents presented as percentage contribution of $\delta_{\mathrm{d}}$ (dispersion force solubility parameter), $\delta_{\mathrm{p}}$ (dipole-dipole interaction solubility parameter), and $\delta_{\mathrm{hb}}$ (hydrogen-bonding solubility parameter).

3.2.3. Condensed-Phase Properties of Individual Compounds. 3.2.3.1. Liquid-Phase Heat Capacity and Solid Heat Capacity at a Constant Pressure. $C_{\mathrm{p}, \mathrm{L}}$ data can be useful to calculate the energy balance of a distillation process, while $C_{\mathrm{p}, \mathrm{S}}$ could be required to calculate the energy balance of a crystallization process. Moreover, $C_{\mathrm{p}, \mathrm{L}}$ has been used as input data for the calculation of the vaporization enthalpy at $298 \mathrm{~K}$ using the TMD VAP ENTH equation. The estimated values of $C_{\mathrm{p}, \mathrm{L}}$ and $C_{\mathrm{p}, \mathrm{S}}$ are given in Table 12. In comparison of the available experimental data for $C_{\mathrm{p}, \mathrm{L}}$ and $C_{\mathrm{p}, \mathrm{S}}$ of the compounds, it can be said that the estimated values are fairly close to the available experimental data, with average absolute percentage differences lower than $10 \%$. The exceptions are phenols and methoxyphenols, for which significantly higher differences (35.4 $\mathrm{J} \mathrm{mol}^{-1} \mathrm{~K}^{-1}$ ) are observed (see Table 12).

3.2.3.2. Liquid-Phase Standard Enthalpy of Formation. The liquid-phase standard enthalpy of formation $\left(\Delta H_{f, \mathrm{~L}}^{\circ}\right)$ is useful to carry out the energy balance of any reaction or process in which the bio-oil takes part. Table 5 shows the experimental values available in the literature for this property, and Table 4 shows the methods used for their calculation.
The results for $\Delta H_{\mathrm{f}, \mathrm{L}}^{\circ}$ using the thermodynamic equation (TMD_LIQ_ENTH), which, in turn, used $\Delta H_{\mathrm{f}, \mathrm{G}}^{\circ}$ and $\Delta H_{\mathrm{vap}, 298 \mathrm{~K}}$ are in very good agreement with the available experimental data (see Table 12). The calculation of $\Delta H_{f, L}^{\circ}$ using the enthalpy balance of the combustion reaction (ENTH_BAL) of each compound (eq S31 of the Supporting Information) offers rough estimations if compared to the experimental values available. Only the $\Delta H^{\circ}, \mathrm{L}$ estimations for the four oligomers are considered to be more accurately determined with this method than with the TMD LIQ ENTH equation, because, as discussed above, the estimated values for $\Delta H_{\text {vap,298 } \mathrm{K}}$ might be overestimated. Furthermore, the enthalpy balance of the combustion reaction requires a smaller number of estimated values than the thermodynamic equation method for the four oligomers. In fact, $\Delta H_{\mathrm{f}, \mathrm{L}}^{\circ}$ of the four oligomers calculated according to the enthalpy balance of their combustion reaction and their $\Delta H_{f, G}^{\circ}$ estimated according to the CBS-QB3 method were used to calculate their $\Delta H_{\mathrm{vap}, 298 \mathrm{~K}}$ obtaining $881.8,595.9,633.5$, and $469.0 \mathrm{~kJ}$ $\mathrm{mol}^{-1}$ for HMM pyrolytic lignin, LMM pyrolytic lignin, humin, and hybrid oligomer, respectively. For HMM pyrolytic lignin, humin, and hybrid oligomer molecules, these values are lower 
Table 14. Molecular Volumes and $A b$ Initio Recommended Diameters for the Surrogate Bio-oil Compounds

\begin{tabular}{lcc}
\multicolumn{1}{c}{ compound } & $\begin{array}{c}\text { ab initio } \\
\left(\mathrm{dm}^{3} \mathrm{kmol}^{-1}\right)\end{array}$ & $\begin{array}{c}\text { recommended } \\
\text { diameter }(\AA)\end{array}$ \\
glycolaldehyde & 46.241 & 6.80 \\
acetol & 59.122 & 7.30 \\
2-cyclopentenone & 68.368 & 7.62 \\
3-methyl-1,2-cyclopentanediene & 82.677 & 8.04 \\
acetic acid & 46.076 & 6.80 \\
propionic acid & 61.634 & 7.38 \\
formic acid & 31.590 & 6.12 \\
furfural & 76.570 & 7.86 \\
2(5H)-furanone & 58.309 & 7.28 \\
phenol & 78.535 & 7.92 \\
guaiacol & 101.384 & 8.54 \\
creosol & 109.712 & 8.74 \\
4-ethylguaiacol & 134.185 & 9.28 \\
eugenol & 138.655 & 9.36 \\
catechol & 77.837 & 7.90 \\
syringol & 118.012 & 8.94 \\
4-methylcatechol & 87.837 & 8.18 \\
vanillin & 112.207 & 8.80 \\
syringaldehyde & 131.659 & 9.22 \\
levoglucosan & 108.160 & 8.70 \\
cellobiosan & 208.438 & 10.58 \\
HMM pyrolytic lignin & 1051.448 & 17.44 \\
LMM pyrolytic lignin & 414.190 & 13.06 \\
humin & 480.389 & 17.66 \\
hybrid oligomer & 986.316 & \\
\hline & & \\
\hline
\end{tabular}

than those calculated according to the thermodynamic equation (TMD VAP ENTH) and more in line with expectations. In the case of LMM pyrolytic lignin, $\Delta H_{\text {vap }, 298 \mathrm{~K}}$ obtained $\left(595.9 \mathrm{~kJ} \mathrm{~mol}^{-1}\right)$ is in good agreement with the value calculated with TMD_VAP_ENTH $\left(534.9 \mathrm{~kJ} \mathrm{~mol}^{-1}\right)$ supporting both estimations. Because these oligomeric molecules would usually be found in the liquid state in most of the processes involving bio-oil, such as the pyrolysis reaction itself, the distillation of bio-oil, or its combustion, the values of $\Delta H_{\mathrm{f}, \mathrm{L}}^{\circ}$ should be used to perform the energy balances. From the observation of the disparity in the $\Delta H_{\mathrm{vap}, 298 \mathrm{~K}}$ values for the oligomeric compounds, especially for HMM pyrolytic lignin, humin, and hybrid oligomer, it is recommended to take $\Delta H_{\mathrm{f}, \mathrm{L}}^{\circ}$ calculated according to the enthalpy balance of the combustion reaction but not the thermodynamic equation (TMD_VAP ENTH) because $\Delta H_{\text {vap,298 } \mathrm{K}}$ is required in this equation.

3.2.3.3. Hansen Solubility Parameters. The Hansen solubility parameters can be used to select appropriate solvents for the extraction of certain fractions of compounds of the biooil, from an analytical and industrial point of view. The solubility behavior of a compound in a solvent is intimately related to the similarity of the resultant intermolecular forces between them. These interactions are represented by the total solubility parameter $\delta_{\mathrm{T}}$ and, more precisely, the similarity of the different intermolecular forces, which are represented in the Hansen solubility parameters $\delta_{\mathrm{d}}$ (dispersion forces), $\delta_{\mathrm{p}}$ (dipole-dipole interactions), and $\delta_{\mathrm{hb}}$ (hydrogen bonding).Table 4 shows the methods used for their estimation.

Experimental values are available only for acetic and formic acids. These can be seen in Table 13 as well as the estimated values of the surrogate bio-oil compounds. Appropriate solvents to extract these compounds from the bio-oil matrix should have similar solubility parameters. According to the comparison of the estimates and the scarce experimental values, the group contribution method of Stefanis and Panayiotou $^{57}$ gives closer estimates to the experimental data than the Hansen first-order group contribution method. ${ }^{58}$

Solubility parameters can also be represented as percentage contributions in a Teas graph, allowing for an easy preliminary selection of solvents. Figure 2 shows the percentage contribution of each intermolecular force for the surrogate bio-oil compounds and some common solvents calculated from the estimates according to Stefanis and Panayiotou. The Hansen solubility parameters of these organic solvents are presented in Table S8 in section S.5 of the Supporting Information.

According to the Teas graph shown in Figure 2, water can be an appropriate solvent to extract the hybrid oligomer, cellobiosan, and levoglucosan thanks to their predisposition to form hydrogen bonds. In comparison of these three molecules, humin presents a lower percentage contribution of the hydrogen-bonding parameter although a higher dipoledipole interaction, allowing for its separation by water extraction. A mixture of methanol or another alcohol and ethyl acetate could be a good option to isolate most of the phenolic compounds because they are in between both solvents in the Teas graph. However, these phenolic compounds would be accompanied by acids; therefore, a combination of separation processes should be applied to isolate them. Dichloromethane and acetone seem to be appropriate solvents for the extraction of 2-cyclopentenone and 3-methyl-1,2-cyclopentanedione. Nonpolar solvents do not seem to be suitable for the extraction of the bio-oil compounds as a result of the significantly higher contribution of the dispersion force in these solvents. Formic acid, pyrolytic lignin, glycolaldehyde, acetol, vanillin, and syringaldehyde seem to have too similar solubility parameter percentage contributions to be isolated individually.

3.2.4. Molecular Properties. 3.2.4.1. Molecular Volume and $A b$ Initio Recommended Diameter. The $a b$ initio diameter of the solute is calculated (with an empirical correction of $0.5 \AA$ ) from its molecular volume assuming a spherical shape. Although such an assumption is hardly correct, the resulting diameter allows for the simple account of solvent effects using the Onsager model and can serve as orientation for the kinetic diameter of molecules. ${ }^{99}$ The kinetic diameter of the molecules is a determining factor for the selection of sieve materials for refining bio-oil in catalytic and separation applications. Separation processes based on molecular sieving or adsorption with resins, such as AmberLite, have already been experimentally studied for the isolation of phenols and levoglucosan. ${ }^{100}$ These types of separation processes could be useful to isolate individually lighter compounds, after their previous concentration from the bio-oil. In this sense, Table 14 shows the molecular volumes and the $a b$ initio recommended diameters, calculated according to the methodology shown in Table 4.

3.2.5. Methods Selected. Table 15 summarizes the methods selected for the calculation/estimation of each property for each chemical family based on the lowest absolute difference with the available experimental values. This selection has only been performed for those properties for whose estimation/ calculation of more than one method has been used.

3.2.6. Assessment of the Proposed Surrogate Composition and the Estimated Thermodynamic Properties. It was 


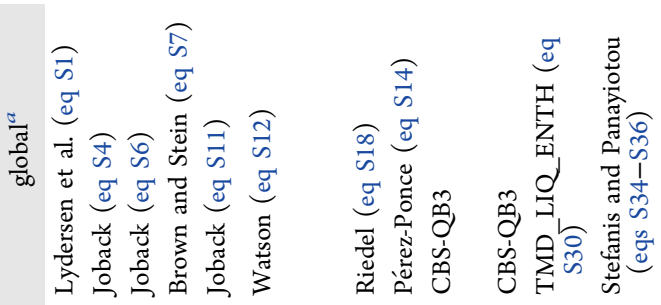

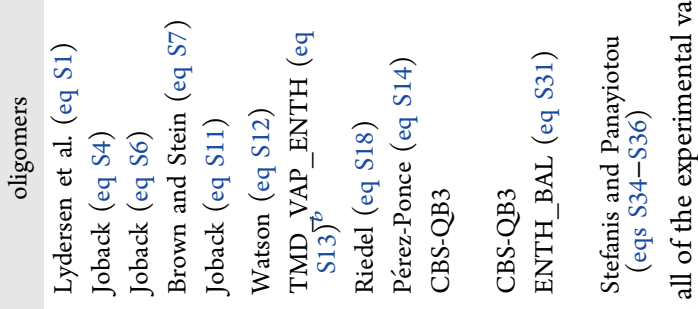

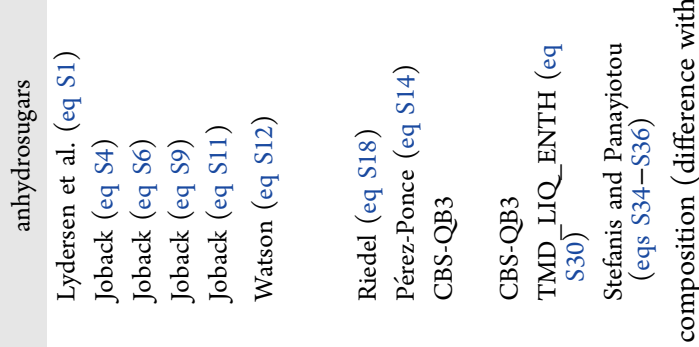

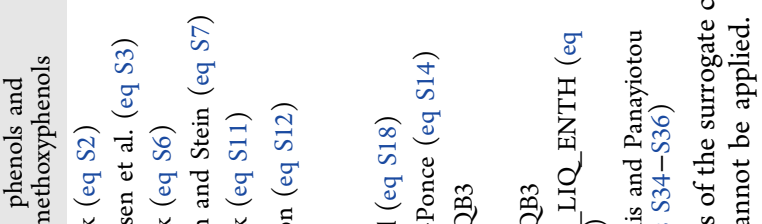

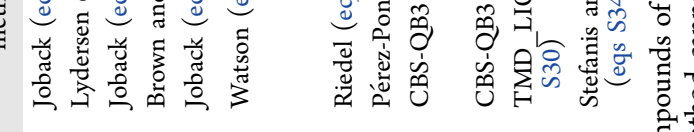

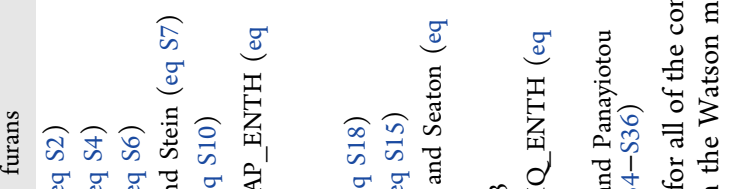

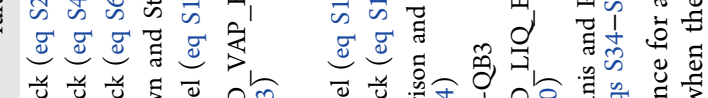

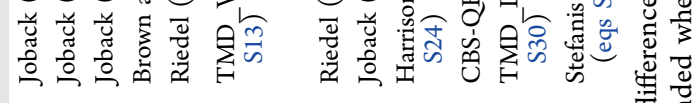

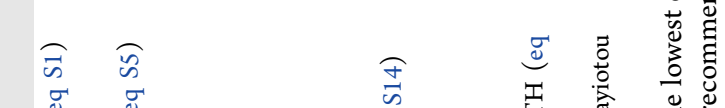

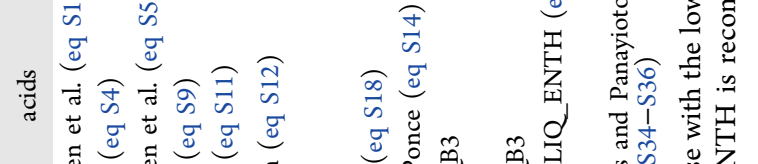

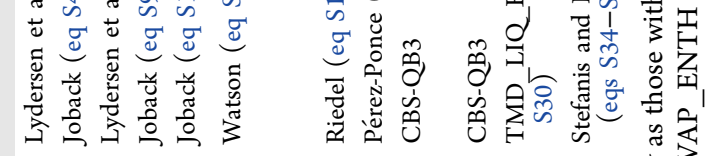
要

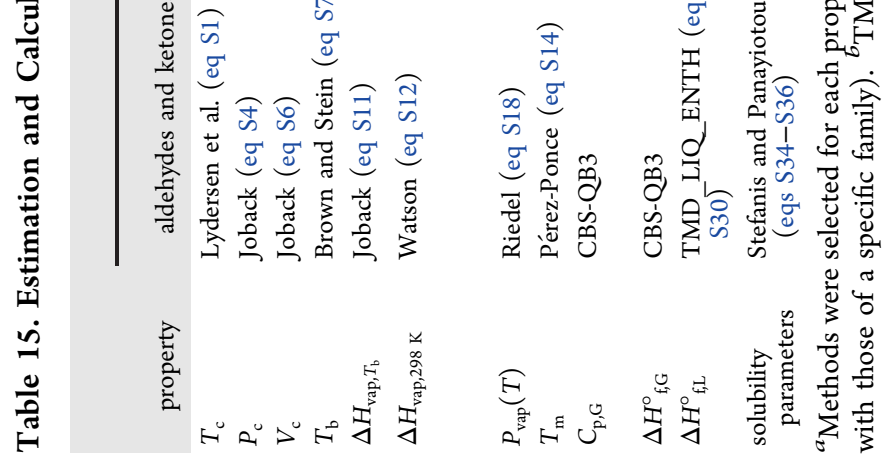


Products at $500{ }^{\circ} \mathrm{C}$

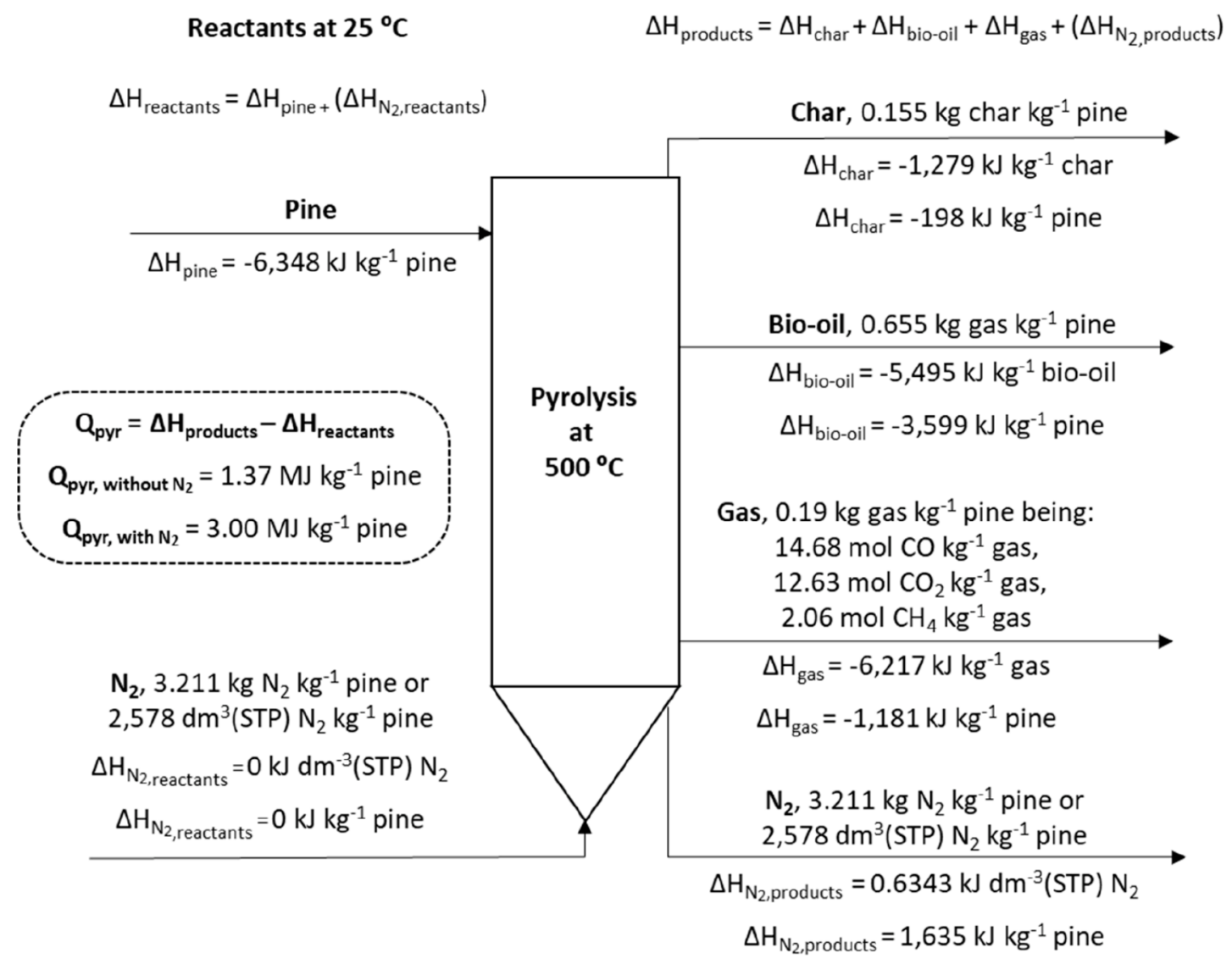

Figure 3. Enthalpy balance of the pyrolysis reaction considering the products at $500{ }^{\circ} \mathrm{C}$.

considered of interest to compare the average apparent enthalpy of formation of the surrogate bio-oil calculated through the individual values proposed in this work (W_AVE, eq S33 of the Supporting Information) to that calculate $\bar{d}$ from the enthalpy balance of its combustion using the experimentally determined HHV of BTG bio-oil, $17.50 \mathrm{MJ} \mathrm{kg}^{-1}$, and its elemental analysis (43.39 wt \% C, 7.37 wt \% H, 0.14 wt \% $\mathrm{N}$, and $49.10 \mathrm{wt} \% \mathrm{O})$ (ENTH_BAL, eq S31 of the Supporting Information).

The average enthalpy of formation of the surrogate bio-oil calculated as the weighted average with the concentrations proposed in this work is $-7215 \mathrm{~kJ} \mathrm{~kg}^{-1}$, while that obtained from the experimental data is $-7156 \mathrm{~kJ} \mathrm{~kg}^{-1}$. The enthalpies of formation calculated by the two methods differ by less than 60 $\mathrm{kJ} \mathrm{kg}^{-1}(0.8 \%)$, which points to a reasonably good agreement. This supports the suitability of the proposed surrogate composition for bio-oil from fast pyrolysis biomass and the estimated properties of the compounds selected because they reproduce the bio-oil enthalpy of formation.

The enthalpy balance of the pyrolysis reaction has been carried out considering pine as the reactant (not $\mathrm{N}_{2}$ used as a carrier gas) at $25^{\circ} \mathrm{C}$ and the products at $500{ }^{\circ} \mathrm{C}$. The enthalpy of each flow of reactant and product at the aforementioned temperatures is shown in Figure 3. This enthalpy balance allows us to calculate that the heat of pyrolysis is $1.37 \mathrm{MJ} \mathrm{kg}^{-1}$ for pine (wet basis), which is in agreement with other values reported in the literature for the fast pyrolysis of pine in a fluidized bed, $1.77 \mathrm{MJ} \mathrm{kg}^{-185}$ or $1.5 \mathrm{MJ} \mathrm{kg}^{-1}$. ${ }^{101}$ This enthalpy balance has also been carried out taking into consideration the heating of $\mathrm{N}_{2}$ used as a carrier gas $\left[3.211 \mathrm{~kg}\right.$ of $\mathrm{N}_{2} \mathrm{~kg}^{-1}$ of pine or $2578 \mathrm{dm}^{3}$ (STP) of $\mathrm{N}_{2} \mathrm{~kg}^{-1}$ of pine taken from ref 85], and in this case, the calculations provide a heat required for pyrolysis of $3.00 \mathrm{MJ} \mathrm{kg}$ of pine, which highlights the significant influence of the heating of $\mathrm{N}_{2}$ used as a fluidizing agent in the overall energy required for pyrolysis. In fact, each kilogram of $\mathrm{N}_{2}$ used as a carrier or fluidizing agent in pyrolysis reactors requires $0.5 \mathrm{MJ}$ to be heated from 25 to $500{ }^{\circ} \mathrm{C}$. This noteworthy influence of the heating of $\mathrm{N}_{2}$ on the overall energy balance of the pyrolysis process should be taken into account in the design of both pyrolysis reactors and condensation systems.

\section{CONCLUSION}

The main conclusions of this work are the following: (1) The composition proposed for the surrogate bio-oil is consistent with the ranges of concentrations reported in the literature for individual compounds, chemical families, and functional groups. In addition, it satisfies the experimental values of the water content and the elemental analysis of the bio-oil. (2) A significant number of thermodynamic, physical, and molecular properties have been estimated using methods from the literature or calculated in this work with $a b$ initio methods. For most of the properties, more than one method has been used to determine their selection. The estimated or calculated properties corresponded well with the available experimental values. On the basis of these comparisons, the most appropriate method of those used for each bio-oil chemical family has been highlighted in the paper. (3) A good 
agreement is obtained between the values of the enthalpy of formation of the bio-oil calculated using the values corresponding to the individual compounds of the surrogate bio-oil and that determined using the experimental HHV $\left(17.50 \mathrm{MJ} \mathrm{kg}^{-1}\right)$ and the elemental analysis of the bio-oil. This agreement between both values supports the suitability of the proposed composition as well as the estimated values of the properties. (4) The composition of the surrogate bio-oil proposed in this work and the estimated values of the properties open up the possibility of simulating or designing thermochemical, separation, and upgrading processes. In fact, they have been used in this work to calculate the heat required for pyrolysis from the enthalpy balance of the pyrolysis reaction, obtaining $1.37 \mathrm{MJ} \mathrm{kg}^{-1}$ of pine without taking into account the energy required to heat $\mathrm{N}_{2}$. The values of the proposed surrogate composition and the values of the estimated/calculated properties provide the foundations for the simulation and design of processes involving bio-oil. However, this property database could be expanded in the future with additional compounds and further properties. (5) To use the proposed surrogate bio-oil composition experimentally, it would be necessary to achieve the isolation of some oligomers, such as humins and hybrid oligomers. The isolation of these molecules, which has not been achieved to date, would also allow for the experimental determination of some of their thermochemical and physical properties.

\section{ASSOCIATED CONTENT}

\section{(s) Supporting Information}

The Supporting Information is available free of charge at https://pubs.acs.org/doi/10.1021/acs.energyfuels.1c01709.

Definition and molecular structures used for the oligomers (section S.1), methodology for $a b$ initio electronic structure calculations (section S.2), nomenclature, equations, and groups considered for the estimation of the properties of the organic compounds according to the different methods (section S.3), tables and figures related to the vapor pressure curves (section S.4), and estimated Hansen solubility parameters of common organic solvents (section S.5) (PDF)

\section{AUTHOR INFORMATION}

\section{Corresponding Author}

Rafael Bilbao - Thermochemical Processes Group (GPT), Aragon Institute for Engineering Research (I3A), Department of Chemical and Environmental Engineering, Universidad de Zaragoza, 50018 Zaragoza, Spain; Email: rbilbao@ unizar.es

\section{Authors}

Isabel Fonts - Thermochemical Processes Group (GPT), Aragon Institute for Engineering Research (I3A), Department of Chemical and Environmental Engineering, Universidad de Zaragoza, 50018 Zaragoza, Spain; Area de Química y Medio Ambiente, Centro Universitario de la Defensa (CUD) de Zaragoza-Academia General Militar, 50090 Zaragoza, Spain; Orcid.org/0000-0001-7035-1955

María Atienza-Martínez - Thermochemical Processes Group (GPT), Aragon Institute for Engineering Research (I3A), Department of Chemical and Environmental Engineering, Universidad de Zaragoza, 50018 Zaragoza, Spain; Grupo de Reactores Químicos y Procesos para la Valorización de
Recursos Renovables, Departamento de Ciencias, Edificio de los Acebos, Universidad Pública de Navarra, 31006 Pamplona, Spain

Hans-Heinrich Carstensen - Fundación Agencia Aragonesa para la Investigación y Desarrollo (ARAID), 50018 Zaragoza, Spain; Department of Chemical and Environmental Engineering, Engineering and Architecture School, University of Zaragoza, 50018 Zaragoza, Spain; (1) orcid.org/0000-0003-0501-7605

Mario Benés - Thermochemical Processes Group (GPT), Aragon Institute for Engineering Research (I3A), Department of Chemical and Environmental Engineering, Universidad de Zaragoza, 50018 Zaragoza, Spain

Anamaria Paiva Pinheiro Pires - Biological Systems Engineering Department, Washington State University, Pullman, Washington 99163, United States

Manuel Garcia-Perez - Biological Systems Engineering Department, Washington State University, Pullman, Washington 99163, United States; 다이.org/0000-00029386-2632

Complete contact information is available at:

https://pubs.acs.org/10.1021/acs.energyfuels.1c01709

\section{Notes}

The authors declare no competing financial interest.

\section{ACKNOWLEDGMENTS}

The authors acknowledge the funding from the Aragón government (reference T22_20R), co-funded by FEDER 2014-2020 “Construyendo Europa desde Aragón”. The authors acknowledge MICINN (RTI2018-098856-B-100) and Centro Universitario de la Defensa (CUD, UZCUD2020-TEC-01) for financial support. Hans-Heinrich Carstensen thanks Aragon Institute of Engineering Research (I3A) for the use of its high performance computing (HPC) cluster HERMES.

\section{REFERENCES}

(1) Pinheiro Pires, A. P.; Arauzo, J.; Fonts, I.; Domine, M. E.; Fernández Arroyo, A.; Garcia-Perez, M. E.; Montoya, J.; Chejne, F.; Pfromm, P.; Garcia-Perez, M. Challenges and Opportunities for Biooil Refining: A Review. Energy Fuels 2019, 33 (6), 4683-4720.

(2) Stankovikj, F.; Garcia-Perez, M. TG-FTIR Method for the Characterization of Bio-oils in Chemical Families. Energy Fuels 2017, 31 (2), 1689-1701.

(3) Stankovikj, F.; McDonald, A. G.; Helms, G. L.; Garcia-Perez, M. Quantification of Bio-oil Functional Groups and Evidences of the Presence of Pyrolytic Humins. Energy Fuels 2016, 30 (8), 6505-6524.

(4) Stankovikj, F.; McDonald, A. G.; Helms, G. L.; Olarte, M. V.; Garcia-Perez, M. Characterization of the Water-Soluble Fraction of Woody Biomass Pyrolysis Oils. Energy Fuels 2017, 31 (2), 16501664.

(5) Terrell, E.; Garcia-Perez, M. Novel Strategy To Analyze Fourier Transform Ion Cyclotron Resonance Mass Spectrometry Data of Biomass Pyrolysis Oil for Oligomeric Structure Assignment. Energy Fuels 2020, 34 (7), 8466-8481.

(6) Staš, M.; Chudoba, J.; Kubička, D.; Blažek, J.; Pospísill, M. Petroleomic Characterization of Pyrolysis Bio-oils: A Review. Energy Fuels 2017, 31 (10), 10283-10299.

(7) Hertzog, J.; Carré, V.; Le Brech, Y.; Dufour, A.; Aubriet, F. Toward Controlled Ionization Conditions for ESI-FT-ICR-MS Analysis of Bio-oils from Lignocellulosic Material. Energy Fuels 2016, 30 (7), 5729-5739. 
(8) Piskorz, J.; Radlein, D. S. A. G.; Scott, D. S.; Czernik, S. Pretreatment of wood and cellulose for production of sugars by fast pyrolysis. J. Anal. Appl. Pyrolysis 1989, 16 (2), 127-142.

(9) Oasmaa, A.; Kuoppala, E.; Solantausta, Y. Fast Pyrolysis of Forestry Residue. 2. Physicochemical Composition of Product Liquid. Energy Fuels 2003, 17 (2), 433-443.

(10) Stankovikj, F.; Tran, C.-C.; Kaliaguine, S.; Olarte, M. V.; Garcia-Perez, M. Evolution of Functional Groups during Pyrolysis Oil Upgrading. Energy Fuels 2017, 31 (8), 8300-8316.

(11) Han, Y.; Gholizadeh, M.; Tran, C.-C.; Kaliaguine, S.; Li, C.-Z.; Olarte, M.; Garcia-Perez, M. Hydrotreatment of pyrolysis bio-oil: A review. Fuel Process. Technol. 2019, 195, 106140.

(12) Zacher, A. H.; Olarte, M. V.; Santosa, D. M.; Elliott, D. C.; Jones, S. B. A review and perspective of recent bio-oil hydrotreating research. Green Chem. 2014, 16 (2), 491-515.

(13) Huber, G. W.; Iborra, S.; Corma, A. Synthesis of transportation fuels from biomass: Chemistry, catalysts, and engineering. Chem. Rev. 2006, 106 (9), 4044-4098.

(14) Kiss, A. A.; Lange, J.-P.; Schuur, B.; Brilman, D. W. F.; van der Ham, A. G. J.; Kersten, S. R. A. Separation technology-Making a difference in biorefineries. Biomass Bioenergy 2016, 95, 296-309.

(15) Ille, Y.; Kröhl, F.; Velez, A.; Funke, A.; Pereda, S.; Schaber, K.; Dahmen, N. Activity of water in pyrolysis oil-Experiments and modelling. J. Anal. Appl. Pyrolysis 2018, 135, 260-270.

(16) Westerhof, R. J. M.; Kuipers, N. J. M.; Kersten, S. R. A.; van Swaaij, W. P. M. Controlling the water content of biomass fast pyrolysis oil. Ind. Eng. Chem. Res. 2007, 46 (26), 9238-9247.

(17) Westerhof, R. J. M.; Brilman, D. W. F.; Garcia-Perez, M.; Wang, Z.; Oudenhoven, S. R. G.; Van Swaaij, W. P. M.; Kersten, S. R. A. Fractional condensation of biomass pyrolysis vapors. Energy Fuels 2011, 25 (4), 1817-1829.

(18) Alviso, D.; Duarte, S.; Alvarenga, N.; Rolón, J. C.; Darabiha, N. Chemical Kinetic Mechanism for Pyrolysis Bio-oil Surrogate. Energy Fuels 2018, 32 (10), 10984-10998.

(19) Pelucchi, M.; Arunthanayothin, S.; Song, Y.; Herbinet, O.; Stagni, A.; Carstensen, H.-H.; Faravelli, T.; Battin-Leclerc, F. Pyrolysis and Combustion Chemistry of Pyrrole, a Reference Component for Bio-oil Surrogates: Jet-Stirred Reactor Experiments and Kinetic Modeling. Energy Fuels 2021, 35 (9), 7265-7284.

(20) Xu, C.; Wang, H.; Oppong, F.; Li, X.; Zhou, K.; Zhou, W.; Wu, S.; Wang, C. Determination of laminar burning characteristics of a surrogate for a pyrolysis fuel using constant volume method. Energy 2020, 190, 116315 .

(21) McVey, M.; Elkasabi, Y.; Ciolkosz, D. Separation of BTX chemicals from biomass pyrolysis oils via continuous flash distillation. Biomass Convers. Biorefin. 2020, 10 (1), 15-23.

(22) Krutof, A.; Hawboldt, K. A. Thermodynamic model of fast pyrolysis bio-oil advanced distillation curves. Fuel 2020, 261, 116446.

(23) Debiagi, P. E. A.; Pecchi, C.; Gentile, G.; Frassoldati, A.; Cuoci, A.; Faravelli, T.; Ranzi, E. Extractives Extend the Applicability of Multistep Kinetic Scheme of Biomass Pyrolysis. Energy Fuels 2015, 29 (10), 6544-6555.

(24) Ranzi, E.; Debiagi, P. E. A.; Frassoldati, A. Mathematical Modeling of Fast Biomass Pyrolysis and Bio-oil Formation. Note I: Kinetic Mechanism of Biomass Pyrolysis. ACS Sustainable Chem. Eng. 2017, 5 (4), 2867-2881.

(25) Ranzi, E.; Debiagi, P. E. A.; Frassoldati, A. Mathematical Modeling of Fast Biomass Pyrolysis and Bio-oil Formation. Note II: Secondary Gas-Phase Reactions and Bio-oil Formation. ACS Sustainable Chem. Eng. 2017, 5 (4), 2882-2896.

(26) Minkin, V. I. Glossary of terms used in theoretical organic chemistry. Pure Appl. Chem. 1999, 71 (10), 1919.

(27) Klamt, A.; Eckert, F.; Arlt, W. COSMO-RS: An alternative to simulation for calculating thermodynamic properties of liquid mixtures. Annu. Rev. Chem. Biomol. Eng. 2010, 1, 101-122.

(28) McGibbon, R. T.; Beauchamp, K. A.; Schwantes, C. R.; Wang, L.-P.; Hernández, C. X.; Herrigan, M. P.; Lane, T. J.; Swails, J. M.; Pande, V. S. MDTraj: A modern, open library for the analysis of molecular dynamics trajectories. bioRxiv 2014, 008896.
(29) Baum, E. J. Chemical Property Estimation: Theory and Application; CRC Press: Boca Raton, FL, 1998.

(30) Choi, Y. S.; Johnston, P. A.; Brown, R. C.; Shanks, B. H.; Lee, K.-H. Detailed characterization of red oak-derived pyrolysis oil: Integrated use of GC, HPLC, IC, GPC and Karl-Fischer. J. Anal. Appl. Pyrolysis 2014, 110, 147-154.

(31) Black, S.; Ferrell, J. R., III Determination of Carbonyl Groups in Pyrolysis Bio-oils Using Potentiometric Titration: Review and Comparison of Methods. Energy Fuels 2016, 30 (2), 1071-1077.

(32) Ferrell, J. R.; Olarte, M. V.; Christensen, E. D.; Padmaperuma, A. B.; Connatser, R. M.; Stankovikj, F.; Meier, D.; Paasikallio, V. Standardization of chemical analytical techniques for pyrolysis bio-oil: History, challenges, and current status of methods. Biofuels, Bioprod. Biorefin. 2016, 10 (5), 496-507.

(33) Oasmaa, A.; Fonts, I.; Pelaez-Samaniego, M. R.; Garcia-Perez, M. E.; Garcia-Perez, M. Pyrolysis Oil Multiphase Behavior and Phase Stability: A Review. Energy Fuels 2016, 30 (8), 6179-6200.

(34) Benés, M.; Bilbao, R.; Santos, J. M.; Alves Melo, J.; Wisniewski, A.; Fonts, I. Hydrodeoxygenation of Lignocellulosic Fast Pyrolysis Bio-oil: Characterization of the Products and Effect of the Catalyst Loading Ratio. Energy Fuels 2019, 33 (5), 4272-4286.

(35) Terrell, E.; Garcia-Perez, M. Vacuum Pyrolysis of Hybrid Poplar Milled Wood Lignin with Fourier Transform-Ion Cyclotron Resonance Mass Spectrometry Analysis of Feedstock and Products for the Elucidation of Reaction Mechanisms. Energy Fuels 2020, 34 (11), 14249-14263.

(36) Kawamoto, H. Lignin pyrolysis reactions. J. Wood Sci. 2017, 63 (2), 117-132.

(37) Jiang, X.; Ellis, N.; Zhong, Z. Fuel properties of bio-oil/biodiesel mixture characterized by TG, FTIR and $1 \mathrm{H}$ NMR. Korean J. Chem. Eng. 2011, 28 (1), 133-137.

(38) Kim, T.-S.; Oh, S.; Kim, J.-Y.; Choi, I.-G.; Choi, J. W. Study on the hydrodeoxygenative upgrading of crude bio-oil produced from woody biomass by fast pyrolysis. Energy (Oxford, U. K.) 2014, 68, 437-443.

(39) Kolská, Z.; Zábranský, M.; Randova, A. Group Contribution Methods for Estimation of Selected Physico-Chemical Properties of Organic Compounds. In Thermodynamics-Fundamentals and Its Application in Science; Morales-Rodriguez, R., Ed.; IntechOpen: London, U.K., 2012; DOI: 10.5772/49998.

(40) Baum, E. J. Chemical Property Estimation: Theory and Application; CRC Press: Boca Raton, FL, 1997; pp 10-20.

(41) Poling, B. E.; Prausnitz, J. M.; O'Connell, J. P. The Properties of Gases and Liquids, 5th ed.; McGraw-Hill Education: New York, 2001; pp 1.3-1.6, A.11.

(42) Montgomery Jr, J. A.; Frisch, M. J.; Ochterski, J. W.; Petersson, G. A. A complete basis set model chemistry. VI. Use of density functional geometries and frequencies. J. Chem. Phys. 1999, 110 (6), 2822-2827.

(43) Curtiss, L. A.; Raghavachari, K.; Redfern, P. C.; Pople, J. A. Assessment of Gaussian-2 and density functional theories for the computation of enthalpies of formation. J. Chem. Phys. 1997, 106 (3), 1063-1079.

(44) Frisch, M. J.; Trucks, G. W.; Schlegel, H. B.; Scuseria, G. E.; Robb, M. A.; Cheeseman, J. R.; Scalmani, G.; Barone, V.; Petersson, G. A.; Nakatsuji, H. L. X.; Caricato, M.; Marenich, A. V.; Bloino, J.; Janesko, B. G.; Gomperts, R.; Mennucci, B.; Hratchian, H. P.; Ortiz, J. V.; Izmaylov, A. F.; Sonnenberg, J. L.; Williams-Young, D.; Ding, F.; Lipparini, F.; Egidi, F.; Goings, J.; Peng, B.; Petrone, A.; Henderson, T.; Ranasinghe, D.; Zakrzewski, V. G.; Gao, J.; Rega, N.; Zheng, G.; Liang, W.; Hada, M.; Ehara, M.; Toyota, K.; Fukuda, R.; Hasegawa, J.; Ishida, M.; Nakajima, T.; Honda, Y.; Kitao, O.; Nakai, H.; Vreven, T.; Throssell, K.; Montgomery, J. A., Jr.; Peralta, J. E.; Ogliaro, F.; Bearpark, M. J.; Heyd, J. J.; Brothers, E. N.; Kudin, K. N.; Staroverov, V. N.; Keith, T. A.; Kobayashi, R.; Normand, J.; Raghavachari, K.; Rendell, A. P.; Burant, J. C.; Iyengar, S. S.; Tomasi, J.; Cossi, M.; Millam, J. M.; Klene, M.; Adamo, C.; Cammi, R.; Ochterski, J. W.; Martin, R. L.; Morokuma, K.; Farkas, O.; Foresman, J. B.; Fox, D. J. Gaussian 16, Revision B.01; Gaussian, Inc.: Wallingford, CT, 2016. 
(45) Lydersen, A. L.; Greenkorn, R. A.; Hougen, O. A. Estimation of Critical Properties of Organic Compounds. Engineering Experiment Station Report 3; College of Engineering, University of Wisconsin: Madison, WI, 1955; pp 1-22.

(46) Joback, K. G. A Unified Approach to Physical Property Estimation Using Multivariate Statistical Techniques. M.S. Thesis, Massachusetts Institute of Technology (MIT), Cambridge, MA, 1984; pp 396.

(47) Stein, S. E.; Brown, R. L. Estimation of normal boiling points from group contributions. J. Chem. Inf. Comput. Sci. 1994, 34 (3), $581-587$.

(48) Riedel, L. Kritischer Koeffizient, Dichte des gesättigten Dampfes und Verdampfungswärme. Untersuchungen über eine Erweiterung des Theorems der übereinstimmenden Zustände. Teil III. Chem. Ing. Tech. 1954, 26 (12), 679-683.

(49) Watson, K. M. Thermodynamics of the Liquid State. Ind. Eng. Chem. 1943, 35 (4), 398-406.

(50) Fishtine, S. H. Need to extend vapor pressure data. Hydrocarbon Process. Petrol. Refin. 1963, 42, 143-144.

(51) Li, P.; Liang, Y.-H.; Ma, P.-S.; Zhu, C. Estimations of enthalpies of vaporization of pure compounds at different temperatures by a corresponding-states group-contribution method. Fluid Phase Equilib. 1997, 137 (1), 63-74.

(52) Pérez Ponce, A. A.; Salfate, I.; Pulgar-Villarroel, G.; PalmaChilla, L.; Lazzús, J. A. New group contribution method for the prediction of normal melting points. J. Eng. Thermophys. 2013, 22 (3), $226-235$.

(53) Riedel, L. Eine neue universelle Dampfdruckformel Untersuchungen über eine Erweiterung des Theorems der übereinstimmenden Zustände. Teil I. Chem. Ing. Tech. 1954, 26 (2), 83-89.

(54) Harrison, B. K.; Seaton, W. H. Solution to missing group problem for estimation of ideal gas heat capacities. Ind. Eng. Chem. Res. 1988, 27 (8), 1536-1540.

(55) Chueh, C. F.; Swanson, A. C. Estimation of liquid heat capacity.

Can. J. Chem. Eng. 1973, 51 (5), 596-600.

(56) Hurst, J. E.; Keith Harrison, B. Estimation of liquid and solid heat capacities using a modified kopp's rule. Chem. Eng. Commun. 1992, 112 (1), 21-30.

(57) Stefanis, E.; Panayiotou, C. Prediction of Hansen Solubility Parameters with a New Group-Contribution Method. Int. J. Thermophys. 2008, 29 (2), 568-585.

(58) Hansen, C. M. Hansen Solubility Parameters: A User's Handbook; CRC Press: Boca Raton, FL, 2007; pp 10-11, 347, 423.

(59) Channiwala, S. A.; Parikh, P. P. A unified correlation for estimating HHV of solid, liquid and gaseous fuels. Fuel 2002, 81 (8), $1051-1063$

(60) Petitjean, M.; Reyes-Perez, E.; Perez, D.; Mirabel, P.; Le Calve, S. Vapor Pressure Measurements of Hydroxyacetaldehyde and Hydroxyacetone in the Temperature Range (273 to 356) K. J. Chem. Eng. Data 2010, 55 (2), 852-855.

(61) Lide, D. R. CRC Handbook of Chemistry and Physics, 90th ed., CRC Press: Boca Raton, FL, 2009; pp 5-4-5-42, 6-51-6-69, 6-1016-118, 6-130-6-139, 15-13-15-22.

(62) Yaws, C. L. Thermophysical Properties of Chemicals and Hydrocarbons; William Andrew Publishing: Norwich, NY, 2009.

(63) Verevkin, S. P. Measurement and prediction of the monocarboxylic acids thermochemical properties. J. Chem. Eng. Data 2000, 45 (5), 953-960.

(64) Majer, V.; Svoboda, V. Enthalpies of Vaporization of Organic Compounds: A Critical Review and Data Compilation; Blackwell Scientific Publications: Oxford, U.K., 1985.

(65) Chao, J.; Zwolinski, B. J. Ideal-gas thermodynamic properties of methanoic and ethanoic acids. J. Phys. Chem. Ref. Data 1978, 7 (1), 363-377.

(66) Emel'yanenko, V. N.; Dabrowska, A.; Hertel, M. O.; Scheuren, H.; Sommer, K. Vapor pressures, enthalpies of vaporization, and limiting activity coefficients in water at $100{ }^{\circ} \mathrm{C}$ of 2 -furanaldehyde, benzaldehyde, phenylethanal, and 2-phenylethanol. J. Chem. Eng. Data 2007, 52 (2), 468-471.
(67) Kudchadker, S. A.; Kudchadker, A. P. Thermodynamic properties of oxygen compounds III. Benzaldehyde and furfural (2furaldehyde). Thermochim. Acta 1975, 12 (4), 432-437.

(68) Ribeiro da Silva, M. A. V.; Santos, A. F. L. O. M.; Amaral, L. M. P. F. A calorimetric and computational study on the thermochemistry of 2- $(5 \mathrm{H})$-furanone and 2-(5H)-thiophenone. J. Chem. Thermodyn. 2010, 42 (4), 564-570.

(69) Matos, M. A. R.; Miranda, M. S.; Morais, V. M. F. Thermochemical study of the methoxy- and dimethoxyphenol isomers. J. Chem. Eng. Data 2003, 48 (3), 669-679.

(70) Ponomarev, D. A.; Oleinikova, T. P.; Masalitinova, T. N. Heat of formation of creosol. Izv. Vyssh. Uchebn. Zaved., Khim. Khim. Tekhnol. 1987, 30, 115-116.

(71) van Roon, A.; Parsons, J. R.; Govers, H. A. J. Gas chromatographic determination of vapour pressure and related thermodynamic properties of monoterpenes and biogenically related compounds. J. Chromatogr. A 2002, 955 (1), 105-115.

(72) Karabaev, M. K.; Abduzhaminov, T. P.; Igamberdiev, K. T.; Turdiev, N. S. Kinetic, thermal, and caloric properties of liquid eugenol. Izv. Akad. Nauk UzSSR, Ser. Fiz.-Mat. Nauk 1983, 4, 72-74.

(73) Stephenson, R. M., Malanowski, S. Handbook of the Thermodynamics of Organic Compounds; Elsevier Science Publishing Co., Inc.: New York, 1987.

(74) Verevkin, S. P.; Kozlova, S. A. Di-hydroxybenzenes: Catechol, resorcinol, and hydroquinone-Enthalpies of phase transitions revisited. Thermochim. Acta 2008, 471 (1-2), 33-42.

(75) Kudchadker, S. A.; Kudchadker, A. P.; Wilhoit, R. C.; Zwolinski, B. J. Ideal gas thermodynamic properties of benzenediols: Pyrocatechol, resorcinol, and hydroquinone. Thermochim. Acta 1979, 30 (1-2), 319-326.

(76) Bret-Dibat, P.; Lichanot, A. Thermodynamic properties of positional isomers of disubstituted benzene in condensed phase. Thermochim. Acta 1989, 147 (2), 261-271.

(77) Ribeiro Da Silva, M. D. M. C.; Ribeiro Da Silva, M. A. V.; Pilcher, G. Enthalpies of combustion of 1,2-dihydroxybenzene and of six alkylsubstituted 1,2-dihydroxybenzenes. J. Chem. Thermodyn. 1984, 16 (12), 1149-1155.

(78) Hoskovec, M.; Grygarova, D.; Cvacka, J.; Streinz, L.; Zima, J.; Verevkin, S. P.; Koutek, B. Determining the vapour pressures of plant volatiles from gas chromatographic retention data. J. Chromatogr. A 2005, 1083 (1-2), 161-172.

(79) Temprado, M.; Roux, M. V.; Chickos, J. S. Some thermophysical properties of several solid aldehydes. J. Therm. Anal. Calorim. 2008, 94 (1), 257-262.

(80) Shoji, T.; Kawamoto, H.; Saka, S. Boiling point of levoglucosan and devolatilization temperatures in cellulose pyrolysis measured at different heating area temperatures. J. Anal. Appl. Pyrolysis 2014, 109, $185-195$.

(81) Kabo, G. J.; Paulechka, Y. U.; Voitkevich, O. V.; Blokhin, A. V.; Stepurko, E. N.; Kohut, S. V.; Voznyi, Y. V. Experimental and theoretical study of thermodynamic properties of levoglucosan. J. Chem. Thermodyn. 2015, 85, 101-110.

(82) Rocha, I. M.; Galvão, T. L. P.; Sapei, E.; Ribeiro da Silva, M. D. M. C.; Ribeiro da Silva, M. A. V. Levoglucosan: A Calorimetric, Thermodynamic, Spectroscopic, and Computational Investigation. J. Chem. Eng. Data 2013, 58 (6), 1813-1821.

(83) Perry's Chemical Engineers' Handbook, 7th ed.; McGraw-Hill Education: New York, 1997; pp 2-139, 2-193, 2-196, 2-221.

(84) DeSisto, W. J.; Hill, N.; Beis, S. H.; Mukkamala, S.; Joseph, J.; Baker, C.; Ong, T.-H.; Stemmler, E. A.; Wheeler, M. C.; Frederick, B. G.; van Heiningen, A. Fast Pyrolysis of Pine Sawdust in a FluidizedBed Reactor. Energy Fuels 2010, 24 (4), 2642-2651.

(85) Daugaard, D. E.; Brown, R. C. Enthalpy for Pyrolysis for Several Types of Biomass. Energy Fuels 2003, 17 (4), 934-939.

(86) Ronewicz, K.; Kluska, J.; Heda, Ł. i.; Kardaś, D. Chemical and Physical Properties of Pine Wood during Pyrolysis. Drvna Ind. 2017, 68 (1), 29-36.

(87) Teixeira, A. R.; Mooney, K. G.; Kruger, J. S.; Williams, C. L.; Suszynski, W. J.; Schmidt, L. D.; Schmidt, D. P.; Dauenhauer, P. J. 
Aerosol generation by reactive boiling ejection of molten cellulose. Energy Environ. Sci. 2011, 4 (10), 4306-4321.

(88) Pecha, M. B.; Terrell, E.; Montoya, J. I.; Stankovikj, F.; Broadbelt, L. J.; Chejne, F.; Garcia-Perez, M. Effect of Pressure on Pyrolysis of Milled Wood Lignin and Acid-Washed Hybrid Poplar Wood. Ind. Eng. Chem. Res. 2017, 56 (32), 9079-9089.

(89) Montoya, J.; Pecha, B.; Janna, F. C.; Garcia-Perez, M. Microexplosion of liquid intermediates during the fast pyrolysis of sucrose and organosolv lignin. J. Anal. Appl. Pyrolysis 2016, 122, 106-121.

(90) Pecha, M. B.; Montoya, J. I.; Chejne, F.; Garcia-Perez, M. Effect of a Vacuum on the Fast Pyrolysis of Cellulose: Nature of Secondary Reactions in a Liquid Intermediate. Ind. Eng. Chem. Res. 2017, 56 (15), 4288-4301.

(91) Montoya, J.; Pecha, B.; Janna, F. C.; Garcia-Perez, M. Identification of the fractions responsible for morphology conservation in lignocellulosic pyrolysis: Visualization studies of sugarcane bagasse and its pseudo-components. J. Anal. Appl. Pyrolysis 2017, 123, 307-318.

(92) Terrell, E.; Dellon, L. D.; Dufour, A.; Bartolomei, E.; Broadbelt, L. J.; Garcia-Perez, M. A Review on Lignin Liquefaction: Advanced Characterization of Structure and Microkinetic Modeling. Ind. Eng. Chem. Res. 2020, 59 (2), 526-555.

(93) Zhang, Y.; Evans, J. R. G.; Yang, S. Corrected Values for Boiling Points and Enthalpies of Vaporization of Elements in Handbooks. J. Chem. Eng. Data 2011, 56 (2), 328-337.

(94) Elkasabi, Y.; Mullen, C. A.; Boateng, A. A. Continuous extraction of phenol and cresols from advanced pyrolysis oils. SN Appl. Sci. 2020, 2 (3), 491.

(95) Elkasabi, Y.; Mullen, C. A.; Boateng, A. A.; Brown, A.; Timko, M. T. Flash Distillation of Bio-oils for Simultaneous Production of Hydrocarbons and Green Coke. Ind. Eng. Chem. Res. 2019, 58 (5), 1794-1802.

(96) Harries, M. E.; McDonald, A. G.; Bruno, T. J. Measuring the distillation curves of non-homogeneous fluids: Method and case study of two pyrolysis oils. Fuel 2017, 204, 23-27.

(97) Yaws, C. L. The Yaws Handbook of Vapor Pressure: Antoine Coefficients, 2nd ed.; Gulf Professional Publishing: Houston, TX, 2015; pp 3, 7, 13, 23, 32, 33, 46, 59, 95, DOI: 10.1016/C2014-003590-3.

(98) Rover, M. R.; Aui, A.; Wright, M. M.; Smith, R. G.; Brown, R. C. Production and purification of crystallized levoglucosan from pyrolysis of lignocellulosic biomass. Green Chem. 2019, 21 (21), 5980-5989.

(99) Mehio, N.; Dai, S.; Jiang, D.-e. Quantum Mechanical Basis for Kinetic Diameters of Small Gaseous Molecules. J. Phys. Chem. A 2014, 118 (6), 1150-1154.

(100) Stanford, J. P.; Hall, P. H.; Rover, M. R.; Smith, R. G.; Brown, R. C. Separation of sugars and phenolics from the heavy fraction of bio-oil using polymeric resin adsorbents. Sep. Purif. Technol. 2018, 194, 170-180.

(101) Yang, H.; Kudo, S.; Kuo, H.-P.; Norinaga, K.; Mori, A.; Mašek, O.; Hayashi, J.-i. Estimation of Enthalpy of Bio-oil Vapor and Heat Required for Pyrolysis of Biomass. Energy Fuels 2013, 27 (5), $2675-2686$. 